\title{
Changing Stress Mindsets with a Novel Imagery Intervention:
}

\section{A Randomized Controlled Trial}

\author{
Jacob J. Keech \\ Griffith University \\ Martin S. Hagger \\ University of California, Merced and University of Jyväskylä \\ Kyra Hamilton \\ Griffith University
}

(C)American Psychological Association, 2019. This paper is not the copy of record and may not exactly replicate the authoritative document published in the APA journal. Please do not copy or cite without authors' permission. The final article will be available, upon publication, via its DOI: $\underline{10.1037 / e m o 0000678}$

Full citation:

Keech, J. J., Hagger, M. S. \& Hamilton, K. (in press). Changing stress mindsets with a novel imagery intervention: A randomized controlled trial. Emotion. doi: 10.1037/emo0000678

\section{Author Note}

Jacob J. Keech, School of Applied Psychology, Menzies Health Institute Queensland, Griffith University, Brisbane, Queensland, Australia; Martin S. Hagger, Psychological Sciences, University of California, Merced, USA and Faculty of Sport and Health Sciences, University of Jyväskylä, Jyväskylä, Finland; Kyra Hamilton, School of Applied Psychology, Menzies Health Institute Queensland, Griffith University, Brisbane, Queensland, Australia

*For correspondence contact: Jacob J. Keech, Health and Psychology Innovations (HaPI) Research Lab, School of Applied Psychology, Griffith University, 176 Messines Ridge Road, Mt Gravatt, QLD 4122, Australia. Email: jacob.keech@griffithuni.edu.au 
Abstract

Objective: Changing individuals' stress mindset has emerged as a technique that may be effective in aiding stress management, but there is limited data on the effects of this technique in managing stress in 'real world' contexts beyond a few days. This study aimed to (1) evaluate the efficacy of a novel imagery-based intervention in changing stress mindset; and, (2) evaluate the effect of the intervention on stress-related outcomes, compared to a control, after two weeks. Methods: The study adopted a pre-registered randomized controlled trial design. University students $(N=150)$ attended a research laboratory twice over two weeks, receiving the intervention or control condition stimuli in Session 1, and completing measures in both sessions. Academic performance data was collected from university records. Results: Mixed model ANOVAs revealed a large-sized difference in stress mindset among intervention group participants immediately following the intervention and at the follow-up relative to controls. There were also robust effects of the intervention on perceived distress, positive and negative affect, proactive behavior, and academic performance at the follow-up in individuals with high baseline perceived distress, although not in the whole sample.

Conclusions: Findings indicate that the intervention is a promising approach for changing individuals' stress mindset and that changing stress mindset can have beneficial effects on coping with ecological stressors. Future research should use intensive longitudinal designs to examine momentary activation of stress mindset and responses to ecological stress.

Study Registration: Open Science Framework https://osf.io/en7q8/

Data Availability Statement: The data, analysis code, analysis output, and study materials are available at the Open Science Framework: https://osf.io/3rz7n/ Keywords: Stress, implicit theories, coping, mental imagery, experiment 
Stress is defined as the feeling of tension that is experienced when an external event or stressor is perceived as outweighing one's capacity to cope afforded by personal resources (Lazarus \& Launier, 1978; Lovallo, 2015). In developed nations such as the United States and Australia, high levels of stress are commonly reported among university students (American College Health Association, 2017; Casey, 2014). Due to the impact of stress on both physical and psychological health (Cohen, Murphy, \& Prather, 2019), and considering that just $13 \%$ of Australians report seeking professional assistance in dealing with stress (Casey, 2014), exploring targets for non-clinical interventions to aid stress management is a research priority. One potential area for non-clinical intervention is changing individuals' stress mindsets.

Mindsets, otherwise known as 'implicit' theories, refer to individuals' beliefs about the malleability of personal qualities, serving as a mental lens through which people judge the meaning of life events (Dweck, Chiu, \& Hong, 1995; Yeager \& Dweck, 2012). Crum, Salovey, and Achor (2013) applied the mindset concept to stress research, finding that stress mindset is related to important stress-related outcomes and distinct from other variables in the stress process, such as amount of stress and stressor appraisal. Stress mindset refers to a set of beliefs held by individuals about the consequences of experiencing stress (Crum et al., 2013; Keech \& Hamilton, 2019). This includes holding the belief that stress can have enhancing consequences for learning and growth, performance and productivity, and health and vitality, which has been associated with more adaptive outcomes under stress (Crum et al., 2013). This contrasts with holding the belief that stress has debilitating consequences, which is associated with poorer outcomes.

Experimental and correlational studies have observed effects of stress mindset on physical and psychological wellbeing, coping behaviors, and affective outcomes in response to laboratory stressor tasks and ecological stress over short periods of time. For example, in an experimental study examining the influence of stress mindset on a range of outcomes in 
response to a laboratory stressor, Crum, Akinola, Martin, and Fath (2017) found that those who were primed with information about the positive consequences of stress exhibited greater positive but not negative affect in anticipation of and following the stressor. Other studies examining the association between stress mindset and health and performance outcomes have shown that those who endorsed a stress-is-enhancing mindset had improved coping behaviors, greater perceived physical health and wellbeing, and better academic performance when experiencing ecological stressors (Casper, Sonnentag, \& Tremmel, 2017; Keech, Hagger, O’Callaghan, \& Hamilton, 2018).

While these studies indicate that stress mindset influences positive outcomes when elicited prior to laboratory-induced stressors and is associated with ecological stressors over a short period of time, it is unclear whether these effects on stress mindset endure beyond these short follow-up periods and whether effects on stress-related outcomes are meaningful in the context of ecological stress over longer periods of time. To advance understanding of how stress mindsets can be leveraged to promote more adaptive responses to stress, it is important to investigate intervention effects in response to ecological stressors over a longer period of time and to use stronger intervention approaches aimed at strengthening these effects.

\section{Interventions to Change Stress Mindsets}

To date, stress mindset interventions have predominately used informational videos aiming to bias attention toward either the enhancing or debilitating properties of stress in separate experimental conditions. For example, Crum et al. $(2013 ; 2017)$ used informational videos that presented stress in either strictly stress-is-enhancing or strictly stress-isdebilitating conditions. These polarized fixed presentations of stress contrast with the nuanced view of stress that was theorized by Crum et al. (2013) as being of value and also with mindset theory more broadly which posit the distinction in mindsets about fundamental attributes to be based on beliefs about the malleability of the attribute (Job, Dweck, \& Walton, 
2010; Yeager \& Dweck, 2012). More recent research has also found that presenting the balanced consequences of stress using informational videos resulted in significantly decreased heart rates and diastolic blood pressure after a lab-induced stressor compared to videos outlining only positive or negative consequences of stress (Liu, Vickers, Reed, \& Hadad, 2017). We therefore contend that interventions aimed at encouraging more adaptive stress mindsets should present that stress "can be" rather than "is" enhancing.

Adopting this view, Keech et al. (2018) tested a stress beliefs model that identified mechanisms through which stress mindset influences outcomes (such as proactive coping behaviors under stress) and suggested that it may be beneficial to intervene upon both stress mindset and proactive coping behavior to strengthen intervention effects. Mental imagery interventions facilitate the process of representing and rehearsing future actions and consequences (Conroy \& Hagger, 2018; Kavanagh, Andrade, \& May, 2005; Pham \& Taylor, 1999) and Conroy and Hagger (2018) provide meta-analytic evidence supporting effects of these interventions on belief-informed constructs and behaviors, and that they are effective even in interventions with relatively low intensity.

Mental imagery is also an effective means of rehearsing and instilling psychological states which, in turn, influence behavior, with interventions of this nature being successfully applied to increasing self-efficacy (Weibull, 2015), increasing motivation (Vasquez, 2007), reducing fear of reinjury in injury rehabilitation (Multhaupt, 2018), and improving affective responses to exercise (Stanley, 2010). Similar to observational learning, mental rehearsal may also stimulate neural networks related to what is being imagined, making them salient and accessible for when the individual finds themselves in a similar situation and having a resultant non-conscious influence on behavior in that later situation (Conroy \& Hagger, 2018; Kosslyn \& Moulton, 2009). This is particularly relevant to interventions aiming to aid individuals in stress management, because dual-process theories of cognition and behavior 
(Evans, 2008; Evans \& Stanovich, 2013; Strack \& Deutsch, 2004) suggest that implicit nonconscious processes are likely to regulate behaviour when working memory is limited (Evans \& Stanovich, 2013), such as when under stress (Banks \& Boals, 2017). Mental imagery may therefore be particularly suited to intervening upon stress mindset and proactive coping behavior simultaneously. The mental imagery technique differs from other visualizationbased strategies such as mental contrasting and implementation intentions (Gollwitzer, 1999) in that the former instructs explicitly comparing current and future (fantasized) states (Oettingen et al., 2009) and the latter instructs the development of concrete "if-then" plans to be evoked in particular situations, while the mental imagery intervention process usually comprises self-directed imagining of specific events or actions, with the purpose of increasing motivation toward the target action (Conroy \& Hagger, 2018).

\section{The Current Study}

The aim of the current pre-registered study was (1) to evaluate the effect of a novel mental imagery-based intervention in changing university students' stress mindsets and (2) to evaluate the effect of the intervention on stress-related outcomes, immediately postintervention, and after two weeks, compared to a control condition. University students from a large Australian university were selected as the target sample for this study because high levels of distress have been observed in large studies of students in Australia (Larcombe et al., 2016) and the prevalence of psychological distress in students in Australia is greater than their non-student peers (Stallman, 2010). Further, in our previous study which sampled students from the same university (Keech et al., 2018), mean perceived distress scores were considerably higher than norms for the perceived stress scale in young adults (Cohen \& Williamson, 1988). We therefore considered this to be a vulnerable population and expected that all individuals would experience at least some benefit from the intervention. In contrast with using a laboratory stressor, the two-week period between intervention and follow-up 
occurred during a university term, and participants navigated their own ecological stressors in this time. The two-week follow-up period was determined based on three key factors. First, there is meta-analytic evidence of a dose effect of mental imagery interventions and specifically that effects can decline over time and that boosters may be required over longer periods (Conroy \& Hagger, 2018). Second, the longest follow-up period for a stress mindset manipulation in the published literature is three days (Crum et al., 2013). We aimed to extend the follow-up period in a modest way to develop an understanding of whether stress mindset can be influenced over a longer period of time. Finally, effects of stress mindset manipulations have been observed on affective, psychological, some behavioral outcomes, and health symptoms over short periods of time (e.g., Crum et al., 2013; 2017). Again, we sought to extend the follow-up period in a modest way in examining the impact of the intervention on these outcomes.

Pre-registered hypotheses. Nine pre-registered hypotheses were tested in the current study. First, it was hypothesized that participants in the intervention condition would experience significantly higher stress mindset scores relative to participants in the control condition (a) immediately post-intervention and (b) at the follow-up two weeks later $\left(\mathrm{H}_{1}\right)$. Turning to the secondary outcomes, it was hypothesized that participants in the intervention condition would experience significantly lower perceived distress $\left(\mathrm{H}_{2}\right)$, higher psychological wellbeing $\left(\mathrm{H}_{3}\right)$, higher positive affect $\left(\mathrm{H}_{4 \mathrm{a}}\right)$, lower negative affect $\left(\mathrm{H}_{4 \mathrm{~b}}\right)$, higher perceived physical health $\left(\mathrm{H}_{5}\right)$, higher proactive behavior $\left(\mathrm{H}_{6}\right)$, lower perceived somatic symptoms $\left(\mathrm{H}_{7}\right)$, higher academic performance $\left(\mathrm{H}_{8}\right)$, and higher academic engagement $\left(\mathrm{H}_{9}\right)$, relative to participants in the control condition from baseline to the two week follow-up.

Theory-guided hypotheses. After conducting the pre-registered analyses and observing non-significant effects of the intervention for the overall sample, we consulted theory to guide further analyses. Specifically, the wise interventions framework provides a 
theoretical framework for testing interventions that target psychological processes (Walton, 2014; Walton \& Wilson, 2018). Consistent with Park et al. (2018), who found that stress mindset moderated the effect of stressful life events on perceived distress, a key vulnerability mechanism targeted by the current intervention was the influence of stressors on distress. However, in the situation that an individual is coping well and not experiencing a considerable level of distress in the presence of a stressor, they may experience little benefit from a wise intervention targeting this stressor to the distress process. A similar issue was encountered by Yeager, Lee, and Jamieson (2016), where the wise intervention being tested was hypothesized to moderate the relationship between daily social-evaluative stressors and neuroendocrine indicators of the stress response, but on some days of the intervention period a relationship between the stressors and the neuroendocrine indicators was not observed. The effect of their intervention was therefore tested for the days where this relationship was observed, and a strong effect of the intervention was found by (Yeager et al., 2016).

Guided by the theory and empirical studies outlined above, we developed further hypotheses to examine whether those with high baseline perceived distress experienced greater benefits from the intervention than those with low baseline perceived distress. Specifically, it was hypothesized that changes in stress mindset across time would be greater in those with high baseline perceived distress. Turning to the secondary outcomes, we also hypothesized that those with high baseline perceived distress would experience greater reductions in perceived distress, increases in psychological wellbeing and positive affect, decreases in negative affect, increases in perceived physical health and proactive behavior, decreases in perceived somatic symptoms, and increases in academic performance and academic engagement over time when exposed to the intervention than those with low baseline perceived distress. 


\section{Method}

The study has been reported in accordance with the CONSORT 2010 checklist for reporting randomized trials (Schulz, Altman, Moher, \& the CONSORT Group, 2010).

\section{Participants}

Participants were young undergraduate university students $(N=150,64 \%$ female $)$ ranging in age from 17 to 25 years $(M=19.11, S D=1.94)$ recruited from a major university in South East Queensland, Australia (see Appendix A, supplementary material for sample demographic characteristics). Participants were recruited through online advertisement, including a university participant pool. Eligibility criteria included age (17-25 years) and current registration as an undergraduate university student. Students received course credit or coffee and department store vouchers as a token of appreciation for their participation.

An a priori power analysis was conducted using $\mathrm{G}^{*}$ Power v3.1 for a mixed model ANOVA estimating fixed effects, main effects, and interactions. The effect size was set to detect a medium effect $(f=.25$ ), with power set to .95 and $\alpha=.01$ (adjusted to protect from inflation of type I error rate due to multiple tests). The total minimum sample size required was $N=90$ (45 participants in each condition). To allow for $40 \%$ attrition, the target sample size was 150 participants at the baseline. A stopping rule was used to govern when to cease recruitment ${ }^{1}$.

\section{Design and Procedure}

The study was pre-registered prior to data collection on the Open Science Framework: https://osf.io/en7q8/. The Griffith University Human Research Ethics Committee approved the study (reference: 2018/019). Data were collected between July and October 2018.

\footnotetext{
${ }^{1}$ Online participant sign-up slots were posted as far in advance as possible for the duration of the study term. Once 100 participants had completed the follow-up survey (to allow for some exclusions due to careless responding), sign-up slots were closed so that no participant can be further booked in to attend and face-to-face and online recruitment ceased. Data collection continued until all participants already signed-up had participated in the study.
} 
Participants visited a university laboratory for two sessions, two-weeks apart. In Session 1, participants received study information and provided informed consent, and then completed baseline measures of study variables followed by the intervention or control condition material. Stress mindset was also measured immediately post-intervention. In Session 2, participants completed follow-up measures. See Figure 1 for full details of the study structure and Appendix B (supplementary material) for the flow of participants through the study. The study adopted a parallel two-group mixed (within-between) randomized controlled design. The study was double-blinded such that both the participant and the experimenter were blinded to the condition to which participants were assigned. The experimenter followed a standardized script and procedure in administering the study to minimize bias. The study was advertised as a study on "understanding beliefs about stress and mental imagery" given that both groups complete a mental imagery task and answer questions about their beliefs about stress. No unintended consequences, harms, or adverse events were reported in the course of the study and there were no deviations from the pre-registered protocol. For further details of the study design and procedure, see the study pre-registration: https://osf.io/en7q8/

Intervention development and optimization. The intervention materials were developed based on examples and mechanisms identified in our prior research (Keech et al., 2018); the three domains of stress mindset (performance and productivity, health and vitality, and learning and growth; Crum et al., 2013); and best-practice techniques for mental imagery interventions (Conroy \& Hagger, 2018; Hamilton, Keech, Peden, \& Hagger, 2019). Prior to recording, the imagery scripts were reviewed by a panel of experts, and by two members of the target population. Based on initial expert and member feedback, refinements to script wording were made. The scripts were then audio-recorded using a voiceover actor and developed into multimedia videos. The videos then underwent further expert review and a rigorous pilot test with members of the target population based on the procedures outlined by 
Hamilton et al. (2019). The pilot involved participants $(n=8)$ completing the baseline survey, the intervention, the post-intervention survey, and then a semi-structured interview where they were asked broadly to share their thoughts and feedback regarding the imagery exercise. The pilot participants were also asked for specific information regarding clarity and timing of the imagery exercises and information presented in the videos. Based on qualitative feedback provided by pilot participants, data-driven refinements to the presentation and timing allocated to the exercises were made. Intervention and control condition videos, scripts, and materials can be accessed on the Open Science Framework: https://osf.io/3rz7n/

Intervention condition. Participants in the intervention condition watched a series videos and then completed a writing exercise as outlined in Figure 1. Part 1 was a brief introduction to the activity. Part 2 provided balanced (negative and positive) information about stress and the consequences of stress. Part 3 was a practice imagery exercise entitled the “tangy lemon" mental imagery task (Holmes \& Mathews, 2005). The purpose of this task was to introduce participants to imagery and allow them to practice prior to the following exercise. Part 4 began with some examples of the positive consequences of stress with regard to six types of stressors identified by students in our prior study (Keech et al., 2018). Part 4 then instructed a process mental imagery exercise, where participants were instructed to think about the potential positive consequences of the stress in their life, and the things they can do to experience these positive consequences. Following this exercise, participants were asked to write down the things that they imagined in the space provided.

Control condition. Participants in the no instruction control condition completed the "tangy lemon" mental imagery task. This was the same as the practice mental imagery task completed by the intervention group.

Randomization. Simple randomization was used with each participant being randomized into to one of two groups. The randomization was conducted by the Qualtrics 
randomization feature following completion of the pre-intervention survey. The Qualtrics randomization feature uses a Mersenne Twister pseudorandom number generator which is seeded using a Unix timestamp (in milliseconds).

\section{Measures}

Stress mindset was measured at baseline, immediately post-intervention, and at the two-week follow-up. All other variables were measured at baseline and at the follow-up. See Appendix C (supplementary material) for details of all measures used in the study.

Stress mindset. Stress mindset was measured using the 15-item Stress Control Mindset Measure (SCMM; Keech et al., 2018).

Perceived distress. Perceived distress was measured using the 10-item Perceived Stress Scale (PSS-10; Cohen \& Williamson, 1988), which measures the extent to which current life situations were perceived as stressful over the preceding two weeks.

Psychological wellbeing. Psychological wellbeing was measured using the 14-item Warwick-Edinburgh Mental Well-being Scale (WEMWBS-14; Tennant et al., 2007) which measures the extent to which people generally experience wellbeing states.

Affect. Positive and negative affect was measured using the 20 -item Positive and Negative Affect Schedule-Short Form (PANAS-SF; Watson, Clark, \& Tellegen, 1988) modified to reference the past two weeks.

Perceived physical health. Perceived physical health was measured using a single item which was the first question from the CDC Health-Related Quality of Life (HRQOL-14; Centers for Disease Control and Prevention., 2000) Healthy Days measure, modified to reference the past two weeks.

Proactive behavior. Proactive behavior was measured using the six-item Proactive Under Stress Scale (Keech et al., 2018) modified to reference the past two weeks.

Perceived somatic symptoms. Perceived somatic symptoms was measured using the 
State-Trait Inventory for Cognitive and Somatic Anxiety (STICSA; Ree, French, MacLeod, \& Locke, 2008) somatic subscale (11 items) as proxy measure for elevation in sympathetic nervous system activation (consistent with Keech et al., 2018). However, rather than in general, the questions were modified to reference the past two weeks for this study.

Academic performance. Academic performance was measured using participants' term grade point average (GPA) for the term prior to participating in the intervention (considered pre-intervention academic performance), and at the end of the term in which participation occurred (considered post-intervention academic performance). Academic terms were 12 weeks in length and, therefore, for practical reasons academic performance was measured on a different scale of time to the other outcome measures. GPA was retrieved from the university system to objectively measure academic performance.

Academic engagement. Academic engagement was measured using the 17-item Utrecht Work Engagement Scale-Student (UWES-S; Schaufeli, Salanova, González-Romá, \& Bakker, 2002) modified to reference the past two weeks.

Baseline participant characteristics. A range of participant characteristics were measured at the baseline to examine variability between the groups: gender, age, marital status, children, study load, employment status, work hours, personal income, English as a second language (ESL), domestic/international student status, and imagery ability.

Data quality questions. Four questions were used to detect careless responding (Maniaci \& Rogge, 2014; Schroder, Dawood, Yalch, Donnellan, \& Moser, 2016), with two used in the questionnaire in each session (e.g., "Please select option two to ensure you are paying attention"). The eight participants who did not answer all four of the questions correctly were excluded prior to data analysis. Visual inspection of the data supported the decision to exclude, with evidence of inattentive responding. 


\section{Pre-Registered Data Analysis Plan}

The effect of the intervention on stress mindset was evaluated using a 2 × 3 mixed model ANOVA in SPSS v.25. Condition/group was the between-subjects independent variable; time (pre-intervention, immediately post-intervention, two-week follow-up) was the within-subjects variable; and stress mindset was the dependent variable. The effect of the intervention on the stress-related outcomes was evaluated using a series of $2 \times 2$ mixed model ANOVAs $^{2}$. Condition/group was the between-participants independent variable; time (preintervention, immediately post-intervention, two-week follow-up) was the within-participants variable; and the stress-related outcomes (psychological wellbeing, perceived distress, positive and negative affect, perceived physical health, proactive behavior, perceived somatic symptoms, academic performance, and academic engagement) were separate dependent variables. Alpha level for inference was adjusted to $\alpha=.01$ to protect from inflation of type I error rate due to multiple tests. Where an ANOVA indicated a significant time $\times$ group interaction for any of the outcome variables, simple effects analyses using estimated marginal means were examined for that outcome. Specifically, within-group differences in the outcome between time points, and between-group differences in the outcome at each time point were compared. Outliers were retained due to no scores falling outside the possible range.

\section{Theory-Guided Data Analysis Procedure}

To understand individual differences in responses to the intervention, and in order to aid in hypothesis generation for future research, a series of analyses guided by the wise interventions framework (Walton, 2014; Walton \& Wilson, 2018) were conducted. It was expected that participants not experiencing a considerable amount of perceived distress may

\footnotetext{
${ }^{2}$ A $2 \times 3$ mixed model ANOVA was used to evaluate the effect of the intervention on stress mindsets because stress mindsets were able to be measured at three time points. Measures of all other outcomes were referenced to the past two weeks and could not be measured both pre-intervention and immediately post-intervention as this would occur in a single session. Therefore, the effect of the intervention on these outcomes was evaluated using $2 \times 2$ mixed model ANOVAs.
} 
already be experiencing positive wellbeing states and, therefore, would be less likely to need to reconsider their beliefs about stress and in turn less likely to experience the same degree of change in stress-related outcomes as those experiencing higher stress. The overall sample was divided into two groups using the median of participants' baseline perceived distress scores. Those with a score less than 20 formed the "low perceived distress" group and those with perceived distress scores greater than or equal to 20 formed the "high perceived distress" group. A series of $2 \times 2 \times 2$ mixed model ANOVAs were run to test all theory-guided hypotheses, with a $2 \times 2 \times 3$ configuration used when stress mindset was the dependent variable. Interaction effects were followed-up with simple effects analyses using estimated marginal means, and $\alpha=.05$ was used as the threshold for statistical significance.

\section{Results}

\section{Pre-Registered Analyses}

Aside from the three participants who were lost to follow-up, there were no missing data on any of the study variables except for academic performance. The extent of missing data for academic performance was $19 \%$ (27 cases) at the baseline and $4 \%$ (six cases) at the follow-up. Little's test indicated that the academic performance data was not missing at random and therefore E-M imputation was not implemented and listwise deletion was used for analyses using academic performance (see footnote 5 for ancillary regression analyses using the full-information maximum likelihood (FIML) procedure. All pre-registered hypotheses were tested using $\alpha=.01$ adjusted to protect against error inflation due to multiple tests. Estimated marginal means, standard errors, and 99\% confidence intervals of study variables by time and group are reported in Table 1. Estimated marginal means are graphically presented in Figure 2 for stress mindset and Appendix D (supplementary materials) for secondary outcomes. Data and output files for all analyses can be accessed on the Open Science Framework: https://osf.io/3rz7n/ 
Stress mindset. A mixed model ANOVA revealed a statistically significant time $\times$ intervention group interaction effect on stress mindset with a large effect size, $F(1.59$, 217.64) $=51.44, p<.001, \eta_{\mathrm{p}}{ }^{2}=.27^{3}$. This indicates that changes in stress mindset across time points were not equivalent between groups and provides support for Hypothesis 1. To probe the interaction effect, simple effects were examined using $99 \%$ confidence intervals about estimated marginal means. There was no significant difference between the intervention and control groups at the baseline $\left(p=.58, \eta_{\mathrm{p}}^{2}=.00\right)$ and the control group did not change over time. However, stress mindset was significantly higher for the intervention group compared to the control group immediately post-intervention $\left(p<.001, \eta_{\mathrm{p}}{ }^{2}=.26\right)$ and at the two-week follow-up $\left(p<.001, \eta_{\mathrm{p}}{ }^{2}=.18\right)$. Stress mindset scores increased significantly for the intervention group from pre-intervention to immediately post-intervention $\left(p<.001, \eta_{\mathrm{p}}{ }^{2}=\right.$ .18). Stress mindset decreased significantly between the measure immediately postintervention and the follow-up; however, the effect size remained large and at a level still significantly greater than pre-intervention.

Secondary outcomes. Turning to the secondary outcomes ${ }^{4}$, mixed model ANOVAs revealed no statistically significant time $\times$ group interaction effects on perceived distress $(F$ $\left.(1,137)=9.75, p=.47, \eta_{\mathrm{p}}^{2}=.00\right)$ psychological wellbeing, $\left(F(1,137)=.00, p=.99, \eta_{\mathrm{p}}^{2}=\right.$ $.00)$; positive affect $\left(F(1,137)=1.16, p=.28, \eta_{\mathrm{p}}^{2}=.01\right)$; negative affect $(F(1,137)=1.46, p$ $\left.=.23, \eta_{\mathrm{p}}^{2}=.01\right)$; perceived physical health $\left(F(1,137)=.58, p=.45, \eta_{\mathrm{p}}^{2}=.00\right)$; proactive behavior $\left(F(1,137)=2.30, p=.13, \eta_{\mathrm{p}}{ }^{2}=.02\right)$; somatic symptoms $(F(1,137)=2.69, p=.25$, $\left.\eta_{\mathrm{p}}^{2}=.00\right)$; academic performance $\left(F(1,107)=1.31, p=.26, \eta_{\mathrm{p}}{ }^{2}=.01\right)$; or academic

\footnotetext{
${ }^{3}$ The Greenhouse-Geiser correction was applied due to Mauchly's test indicating sphericity cannot be assumed.

${ }^{4}$ There were no significant differences between the intervention and control groups at the baseline for any of the secondary outcomes, including perceived distress $\left(p=.12, \eta_{\mathrm{p}}{ }^{2}=.02\right)$, psychological wellbeing $\left(p=.08, \eta_{\mathrm{p}}{ }^{2}=\right.$ $.02)$, positive affect $\left(p=.27, \eta_{\mathrm{p}}{ }^{2}=.01\right)$, negative affect $\left(p=.32, \eta_{\mathrm{p}}{ }^{2}=.01\right)$, physical health $\left(p=.33, \eta_{\mathrm{p}}{ }^{2}=.01\right)$, proactive behavior $\left(p=.08, \eta_{\mathrm{p}}{ }^{2}=.02\right)$, perceived somatic symptoms $\left(p=.46, \eta_{\mathrm{p}}{ }^{2}=.00\right)$, academic performance $\left(p=.08, \eta_{\mathrm{p}}{ }^{2}=.03\right)$, and academic engagement $\left(p=.63, \eta_{\mathrm{p}}^{2}=.00\right)$.
} 
engagement $\left(F(1,137)=1.20, p=.28, \eta_{\mathrm{p}}{ }^{2}=.01\right)$. Effect sizes were also consistently small.

Therefore, Hypotheses 2 to 9 were rejected ${ }^{5}$.

\section{Theory-Guided Analyses}

Following the pre-registered analyses with the whole sample, a series of theory-guided analyses were conducted which divided the sample into two subgroups: a high baseline perceived distress subgroup and a low baseline perceived distress subgroup. The analysis procedure is described in the Method section. Effects of the intervention described below were observed only in individuals in the high perceived distress subgroup. Estimated marginal means, standard errors, and 95\% confidence intervals of study variables by time and subgroup are reported in Table 2, and estimated marginal means are graphically presented in Figures 2 4.

Stress mindset. A three-way mixed model ANOVA revealed a significant time $\times$ group $\times$ baseline perceived distress interaction effect on stress mindset, $F(6,270)=17.73, p$ $<.001, \eta_{\mathrm{p}}{ }^{2}=.28$. This indicates that changes in stress mindset across time points between the intervention and control group were different for those with high and low levels of baseline perceived distress. To probe the interaction effect, simple effects were examined. Estimated marginal means indicated that there were no significant baseline differences in stress mindset between the control and intervention groups for those with low baseline perceived distress $(p$ $\left.=.128, \eta_{\mathrm{p}}^{2}=.02\right)$, or high baseline perceived distress $\left(p=.055, \eta_{\mathrm{p}}^{2}=.03\right)$. However, there was a significant difference between the control and intervention groups for those with low

\footnotetext{
${ }^{5}$ Baseline levels of psychological wellbeing, proactive behavior, and academic performance approached conventional levels indicating statistically significant differences, which may compromise internal validity. There was also missing academic performance data. For completeness, ancillary analyses were conducted in $R$ (R Core Team, 2019) using the lavaan (Rosseel, 2012) package to control for baseline differences in the preregistered analyses and to estimate values for the missing academic performance data. The ancillary analyses were regression analyses for each of the Time 2 dependent variables, controlling for baseline levels of psychological wellbeing, proactive behavior, academic performance, and the dependent variable in each analysis. Missing data was estimated using the full-information maximum likelihood (FIML) procedure. There were no differences in the pattern of effects for any of the dependent variables, with the exception that in the analysis predicting proactive behavior, the effect of group was approaching our specified cutoff for statistical significance $(p=.027)$. Readers are directed to the online supplemental material for details of these analyses.
} 
perceived distress $\left(p=.001, \eta_{\mathrm{p}}^{2}=.07\right)$ and high perceived distress $\left(p<.001, \eta_{\mathrm{p}}{ }^{2}=.25\right)$ immediately post-intervention, and at the two-week follow-up such that the intervention had a stronger effect on those in the high perceived distress group $\left(p<.001, \eta_{\mathrm{p}}{ }^{2}=.17\right)$ than those in the low perceived distress group $\left(p=.018, \eta_{\mathrm{p}}^{2}=.04\right)$.

Secondary outcomes. Three-way mixed model ANOVAs revealed statistically significant time $\times$ group $\times$ baseline perceived distress effects on perceived distress, $F(3,135)$ $=9.69, p<.001, \eta_{\mathrm{p}}{ }^{2}=.18 ;$ psychological wellbeing, $F(3,135)=3.31, p=.022, \eta_{\mathrm{p}}{ }^{2}=.07$; positive affect, $F(3,135)=3.17, p=.027, \eta_{\mathrm{p}}^{2}=.07$; proactive behavior, $F(3,135)=4.37, p$ $=.006, \eta_{\mathrm{p}}^{2}=.09 ;$ and academic performance, $F(3,105)=2.97, p=.035, \eta_{\mathrm{p}}^{2}=.08^{6}$. The time $\times$ group $\times$ baseline distress interaction effect on negative affect fell just short of the conventionally-accepted level for statistical significance; however, a medium-sized effect was observed, $F(3,135)=2.66, p=.051, \eta_{\mathrm{p}}{ }^{2}=.06$. This indicates that changes in perceived distress, psychological wellbeing, positive affect, proactive behavior, academic performance, and potentially negative affect across time points between the intervention and control group were different for those with high and low levels of baseline perceived distress. Estimated marginal means indicated that there were no significant differences in perceived distress, psychological wellbeing, positive affect, proactive behavior, academic performance, and negative affect between the control and intervention groups for those with low perceived distress or high perceived distress at the baseline ${ }^{7}$.

Probing the interaction effects revealed that there were no significant differences in

\footnotetext{
${ }^{6}$ For completeness, the effect of the intervention on each subgroup was examined using a multi-group regression analysis in $R$ (R Core Team, 2019) using the lavaan (Rosseel, 2012) package to estimate missing data with the FIML procedure.

${ }^{7}$ Low perceived distress group: perceived distress $\left(p=.396, \eta_{\mathrm{p}}{ }^{2}=.01\right)$, psychological wellbeing $\left(p=.892, \eta_{\mathrm{p}}{ }^{2}=\right.$ $.00)$, positive affect $\left(p=.717, \eta_{\mathrm{p}}{ }^{2}=.00\right)$, proactive behavior $\left(p=.524, \eta_{\mathrm{p}}{ }^{2}=.00\right)$, academic performance $(p=$ $\left..174, \eta_{\mathrm{p}}^{2}=.02\right)$, and negative affect $\left(p=.880, \eta_{\mathrm{p}}^{2}=.00\right)$. High perceived distress group: perceived distress $(p=$ $\left..124, \eta_{\mathrm{p}}{ }^{2}=.02\right)$, psychological wellbeing $\left(p=.141, \eta_{\mathrm{p}}{ }^{2}=.02\right)$, positive affect $\left(p=.420, \eta_{\mathrm{p}}{ }^{2}=.01\right)$, proactive behavior $\left(p=.281, \eta_{\mathrm{p}}{ }^{2}=.01\right)$, academic performance $\left(p=.300, \eta_{\mathrm{p}}{ }^{2}=.01\right)$, and negative affect $\left(p=.975, \eta_{\mathrm{p}}{ }^{2}=\right.$ $.00)$.
} 
perceived distress $\left(p=.868, \eta_{\mathrm{p}}{ }^{2}=.00\right)$, psychological wellbeing $\left(p=.915, \eta_{\mathrm{p}}{ }^{2}=.00\right)$, positive affect $\left(p=.898, \eta_{\mathrm{p}}{ }^{2}=.00\right)$, proactive behavior $\left(p=.546, \eta_{\mathrm{p}}{ }^{2}=.00\right)$, academic performance $(p$ $\left.=.653, \eta_{\mathrm{p}}{ }^{2}=.00\right)$, and negative affect $\left(p=.876, \eta_{\mathrm{p}}{ }^{2}=.00\right)$ between the control and intervention groups at the follow-up in those with low baseline perceived distress. For those with high perceived distress at the baseline, the intervention group had significantly lower perceived distress $\left(p=.014, \eta_{\mathrm{p}}^{2}=.04\right)$, higher positive affect $\left(p=.037, \eta_{\mathrm{p}}{ }^{2}=.03\right)$, higher proactive behavior $\left(p=.001, \eta_{\mathrm{p}}^{2}=.08\right)$, higher academic performance $\left(p=.021, \eta_{\mathrm{p}}^{2}=.05\right)$, and lower negative affect $\left(p=.035, \eta_{\mathrm{p}}^{2}=.03\right)$ than the control group at the follow-up.

Further, for those with high perceived distress at the baseline, the intervention group exhibited higher psychological wellbeing than the control group at the follow-up, however, the difference was not significant $\left(p=.138, \eta_{\mathrm{p}}^{2}=.02\right)$.

Three-way mixed model ANOVAs revealed no time $\times$ group $\times$ baseline perceived distress interaction effects on perceived physical health, $F(3,135)=1.34, p=.266, \eta_{\mathrm{p}}^{2}=.03$; perceived somatic symptoms, $F(3,135)=.39, p=.763, \eta_{\mathrm{p}}^{2}=.01$; and academic engagement, $F(3,135)=1.17, p=.325, \eta_{\mathrm{p}}^{2}=.03$. This indicates that changes in negative affect, perceived physical health, perceived somatic symptoms, and academic engagement across time points between the intervention and control group were not different for those with high and low levels of baseline perceived distress. Estimated marginal means indicated that there were no significant differences in negative affect, perceived physical health, perceived somatic symptoms, and academic engagement between the control and intervention groups for those with low perceived distress or high perceived distress at the baseline ${ }^{8}$.

\section{Further Analyses}

Following the mental imagery exercise, intervention group participants were asked to

\footnotetext{
${ }^{8}$ Low perceived distress group: perceived physical health $\left(p=.456, \eta_{\mathrm{p}}{ }^{2}=.00\right)$, perceived somatic symptoms $(p$ $\left.=.850, \eta_{\mathrm{p}}{ }^{2}=.00\right)$, and academic engagement $\left(p=.663, \eta_{\mathrm{p}}{ }^{2}=.00\right)$. High perceived distress group: perceived physical health $\left(p=.284, \eta_{\mathrm{p}}{ }^{2}=.01\right)$, perceived somatic symptoms $\left(p=.836, \eta_{\mathrm{p}}{ }^{2}=.00\right)$, and academic engagement $\left(p=.532, \eta_{\mathrm{p}}^{2}=.00\right)$.
} 
note down a few sentences summarizing what they visualized. We examined this data to develop an understanding of: (1) whether participants in the intervention group were able to imagine a stressor and the things they can do to experience the potential positive consequences of the stressor; and, (2) whether participants in the intervention group made specific mention of the potential positive consequences of their stressor during the imagery exercise which may provide insight into the potential for demand characteristics influencing stress mindset scores. With regard to the first question, all participants in the intervention group reported visualizing a stressor during the mental imagery exercise. This suggests that while not all participants were experiencing significant distress, they were all experiencing stressors that they were able to consider in completing the imagery exercise. With regard to the second question, $76 \%$ of participants in the intervention group made specific mention of the positive consequences of stress, while the remaining $24 \%$ simply described the things they thought about doing. We speculate that instruction regarding the positive consequences of stress was more salient for those that made specific mention of positive consequences in their descriptions. Therefore, it could be expected that if demand characteristics were having a meaningful impact on post-intervention stress mindset scores, the individuals for who this was more salient would exhibit a greater change in stress mindset scores. However, an independent samples $t$-test revealed no significant difference in average change in stress mindset scores (from pre to immediately post-intervention) between those who mentioned positive consequences of stress in their imagery descriptions $(M=.95, S D=.73)$ and those who did not $(M=1.02, S D=1.06), t(69)=-.32, p=.749$. This is further supported by the distribution of stress mindset scores on individual items immediately post-intervention. For all items, a small proportion of participants in the intervention group (between $2.80 \%$ and $16.70 \%)$ selected the highest scale point $(M=7.67 \%, S D=4.48)$. 


\section{Discussion}

The purpose of the current study was to develop and test the efficacy of a novel mental imagery-based intervention in changing stress mindsets immediately post-intervention, and at a two-week follow-up using a pre-registered randomized controlled design. The study also aimed to evaluate the effect of the intervention on a range of health and performance-related outcomes. As predicted, the intervention yielded a large effect on stress mindset immediately post-intervention which was maintained at the two-week follow-up. Contrary to expectations, no effect of the intervention from baseline to the two-week follow-up was observed for any of the secondary health and performance-related outcomes for the pre-registered analyses of the whole sample. While estimated marginal means of the outcomes were more favorable in the expected directions for those in the intervention group at follow-up, effect sizes were small and did not reach conventional levels of statistical significance. Subsequent theory-guided analyses based on subgroups indicated that the intervention demonstrated robust effects on perceived distress, positive and negative affect, proactive behavior, and academic performance at the follow-up in individuals with high baseline perceived distress. These effects on secondary outcomes were not observed in those with low perceived distress, or in the overall sample. Effects of the intervention on stress mindset were also stronger in individuals with high baseline perceived distress.

Current findings have several important theoretical and practical implications, with implications for future research. This study is the first to establish the efficacy of a mental imagery-based intervention to effect a change in stress mindset that was retained at a twoweek follow-up. This builds on existing stress mindset manipulations which have focused on eliciting an attentional bias toward the positive consequences of stress and have been followed-up a few days post-intervention (e.g., Crum et al., 2017; Crum et al., 2013). Results indicate that mindset change beyond a brief attentional bias is possible in the context of stress 
mindset. It should be noted, however, that at the two-week follow-up the effect size of the intervention on stress mindset was smaller, suggesting that the strength of the effect declined over time. This may be due to beliefs not being reinforced over the two-week period; or, consistent with prior research, an attentional bias toward positive stress-related information being induced immediately following the intervention that dissipates over time (e.g., Crum et al., 2017; Crum et al., 2013). To better understand these processes, future research should examine the trajectory of stress mindsets over a longer period of time following the intervention and consider increasing the dose through the use of additional imagery sessions across the study period. Research should also seek to test the potential mechanisms that determine the induction of a stress mindset, and its subsequent decay, over time, by including measures of attentional bias toward positive interpretation of stress-related information and conducting mediation analyses.

In contrast to our pre-registered hypotheses, no effect of the intervention on the secondary outcomes at the two-week follow-up was detected for the pre-registered analyses of the whole sample. A possible explanation for this is that despite all participants reporting exposure to stressors, there was considerable heterogeneity in baseline levels of distress among the overall sample. Subsequent analyses guided by the wise interventions framework (Walton, 2014; Walton \& Wilson, 2018) and prior research revealed robust effects of the intervention on perceived distress, positive and negative affect, proactive behavior, and academic performance at the follow-up in individuals with high baseline perceived distress. It is likely that individuals with low baseline perceived distress were already coping well and had little need to apply what they had learned in the intervention. Park and colleagues' (2018) findings indicate that stress mindset moderates the effect of stressful life events on perceived distress and, therefore, where individuals' exposure to stressors is not currently leading to distress, there is no psychological mechanism of vulnerability for the wise intervention to 
yield an effect on. Yeager et al. (2016) also observed no effect of an incremental theories of personality intervention on neuroendocrine outcomes on days when stressor exposure was not influencing these outcomes. This is not to suggest that those not experiencing distress would never benefit from the intervention tested in the current study; however, examining potential stress inoculation benefits in these individuals would require longitudinal research over an extended period of time and would be best examined independently of studying distressed individuals.

While trends in the predicted directions were observed, no statistically significant effect of the intervention was observed on psychological wellbeing, perceived physical health and somatic symptoms, and academic engagement in high baseline perceived distress individuals, which contrasted with our theory-guided hypotheses. There are several possible explanations for this lack of observed effect. The study used retrospective recall of wellbeing, affective states, and behavior over a two-week period which may not adequately capture momentary responses to stressors. Momentary responses to ecological stressors may in fact be similar to the momentary responses to laboratory stressors observed in prior research (e.g., Crum et al., 2017; Crum et al., 2013) and they may not necessarily be captured through retrospective recall at the end of a two-week period. Beyond potential issues with retrospective recall, a longer period of time may be required for changes in momentary responses to ecological stress to translate into overall improvements in these outcomes. For example, impacts of distress on physical health tend to occur with chronic stress over longer periods of time (Cohen, Gianaros, \& Manuck, 2016). Prior research has observed effects of a stress mindset manipulation on health symptoms (Crum et al., 2017; Crum et al., 2013), which may be more proximal to when an individual experiences stress. Further, behaviors such as academic engagement may involve complex self-regulatory processes, for example habits around procrastination, and these may require more time and simultaneous intervention 
upon other mechanisms to change (Schnauber-Stockmann, Meier, \& Reinecke, 2018).

Together, these findings provide further insight into when stress mindset interventions may be beneficial for improving stress-related outcomes. Specifically, the findings indicate that there may be a requisite baseline level of perceived distress for the induction of a stress mindset to make observable differences in adaptive outcomes such as wellbeing, affect, behavior, and performance. This extends upon current knowledge from studies that have observed beneficial effects of stress mindset interventions in response to laboratory-induced stressors that are designed to be as uniform as possible (e.g., Crum et al., 2017; Crum et al., 2013). The current study is the first to examine the effect of a stress mindset intervention on stress-related outcomes in response to an ecologically-valid setting beyond a few days and, therefore, these findings should be replicated and extended upon in future pre-registered studies of individuals with high perceived stress. To address the questions outlined above, future research should also seek to use methods such as ecological momentary assessment (Bolger \& Laurenceau, 2013) to measure stress mindsets, wellbeing, affective responses, and behavior to examine within-subjects trajectories of these constructs when ecological stress is experienced prior to and following the intervention. It would also be valuable in future research to test mediation models to examine whether changes in the stress-related outcomes in those who receive the intervention occur via changes in stress mindset, or whether there are other processes that may explain these effects.

\section{Study Strengths and Limitations}

The current study has several strengths that enhance understanding of the effects of stress mindsets on health and performance outcomes. First, the study tested a novel imagerybased intervention which was rigorously pilot tested and informed by prior research into stress mindset (Keech et al., 2018), and best practice guidelines for imagery interventions (Conroy \& Hagger, 2018; Hamilton et al., 2019). Second, the study sought to minimize bias 
using a pre-registered double-blinded randomized controlled trial design. Third, the study used student grade point average (GPA) scores from university student records to provide an objective measure of academic performance.

Current findings should also be considered in light of some limitations. First, with the exception of academic performance, measures of the secondary outcomes relied on retrospective recall of behavioral and affective states. While the self-report measures used have adequate validity and reliability, they do not allow for a fine-grained examination of how stress mindsets may affect stress responses in a given moment. Future research using ecological momentary assessment methods (Bolger \& Laurenceau, 2013) may help to overcome this limitation by frequently measuring exposure to stressors and momentary responses prior to and following a stress mindset intervention.

For the pre-registered hypotheses, all effects were considerably smaller than anticipated, and power and sample size were not calculated for the scenario of conducting subgroup analyses which divide the size of the sample. It is possible, therefore, that the study was not sufficiently powered to detect potentially smaller effects of the intervention on psychological wellbeing, perceived physical health, perceived somatic symptoms, and academic performance. An important direction for future research is to replicate these findings in another pre-registered study sampling individuals' experiencing high levels of distress (i.e., through screening potential participants) to ensure a sufficiently powered sample is recruited to examine the effects of the intervention on those who are likely to benefit most.

In an effort to minimize demand characteristics, the current study was designed to blind participants regarding the aims and the fact that the study was an intervention. As opposed to providing firm instruction to persuade participants that stress is positive, the intervention exercises were designed to encourage participants to consider that stress can have positive consequences and to consider potential positive consequences of the stress they are 
experiencing. We therefore expected that considering this would lead to a change in stress mindset for individuals who were able to visualize positive consequences of their stress and that changes in mindset scores would be unlikely to be due to demand characteristics.

Examination of item distributions on the measure of stress mindset and analysis of qualitative data from intervention group participants provides some evidence to support this assertion. Further, a large-sized change in stress mindset was maintained at the two-week follow-up, where we expect that the aims of the experiment, if guessed by participants, would have been less salient and therefore less likely to influence responses to the measure of stress mindset. While this information provides some evidence that changes in stress mindset scores were not due to demand characteristics, they cannot be entirely ruled out.

A further limitation of the design of the current study is that we did not control for differences in expectancy effects between conditions due to factors such as credibility of the stimuli as an intervention, expectancy of outcomes, and time and effort. Given that expected success in emotion regulation is a well-established determinant of actual emotion regulation (Bigman, Mauss, Gross, \& Tamir, 2016; Tamir, Bigman, \& Pietromonaco, 2018; Tamir, Bigman, Rhodes, Salerno, \& Schreier, 2015), it is important that possible expectancy effects are accounted for in future tests of this intervention. This could be implemented by designing a placebo control condition that is matched with the intervention condition on credibility of the stimuli as an intervention, on the expected benefits of having been exposed to the stimuli, and on the time and effort required for exposure to the stimuli.

\section{Conclusion}

The current study provided the first test of a mental-imagery based stress mindset intervention. The intervention had a large effect on stress mindset scores immediately postintervention and although stress mindset had started to decline, a large effect was retained after two weeks. While changes in the secondary outcomes were in the expected directions for 
the pre-registered analyses, they were not statistically significant for the overall sample and this is likely due to not all individuals experiencing the stress response in the intervention period. Further theory-guided analyses indicated that there were robust effects of the intervention on perceived distress, positive and negative affect, proactive behavior, and academic performance at the follow-up in individuals with high baseline perceived distress. Together, these findings show that the intervention is a promising approach to changing individuals' stress mindset and that changing stress mindset can have beneficial effects on coping with ecological stressors. Further research is needed to replicate and extend these findings in a sample of individuals experiencing high levels of distress and to eliminate the potential role of expectancy effects in influencing the outcomes under investigation. To better understand the role of stress mindsets in managing ecological stressors, future research should employ ecological momentary assessment to measure exposure to stressors and momentary responses prior to and following a stress mindset intervention. This method can also aid in understanding trajectories of stress mindset following an intervention, including whether booster doses are required to create longer term mindset change, and whether the mindsets are activated and salient in stressful situations.

\section{Acknowledgements and Funding}

This research did not receive any specific grant from funding agencies in the public, commercial, or not-for-profit sectors. Jacob J. Keech's contribution was supported by the Australian Government Research Training Program. Martin S. Hagger's contribution was supported by a Finland Distinguished Professor (FiDiPro) award (Dnro 1801/31/2105) from Business Finland. We would like to thank Kevin Judge (Senior Technical Officer - Health, Griffith University) for recording and producing the videos that delivered the intervention and control condition stimuli. We would also like to thank Andrew Campbell for his assistance with data collection. 


\section{References}

American College Health Association. (2017). American College Health AssociationNational College Health Assessment II: Reference Group Executive Summary Fall 2016. Hanover, MD: American College Health Association.

Banks, J. B., \& Boals, A. (2017). Understanding the role of mind wandering in stress-related working memory impairments. Cognition and Emotion, 31(5), 1023-1030. doi: 10.1080/02699931.2016.1179174

Bigman, Y. E., Mauss, I. B., Gross, J. J., \& Tamir, M. (2016). Yes I can: Expected success promotes actual success in emotion regulation. Cognition and Emotion, 30(7), 13801387. doi: 10.1080/02699931.2015.1067188

Bolger, N., \& Laurenceau, J.-P. (2013). Intensive longitudinal methods: An introduction to diary and experience sampling research. New York, NY: Guilford.

Casey, L. (2014). Stress and wellbeing in Australia survey 2014. Melbourne, Australia: Australian Psychological Society.

Casper, A., Sonnentag, S., \& Tremmel, S. (2017). Mindset matters: the role of employees' stress mindset for day-specific reactions to workload anticipation. European Journal of Work and Organizational Psychology, 1-13. doi: 10.1080/1359432X.2017.1374947

Centers for Disease Control and Prevention. (2000). Measuring healthy days: Population assessment of health-related quality of life. Atlanta, GA.

Cohen, S., Gianaros, P. J., \& Manuck, S. B. (2016). A stage model of stress and disease. Perspectives on Psychological Science, 11(4), 456-463. doi:

\section{$10.1177 / 1745691616646305$}

Cohen, S., Murphy, M. L. M., \& Prather, A. A. (2019). Ten surprising facts about stressful life events and disease risk. Annual Review of Psychology, 70(1), 577-597. doi: 10.1146/annurev-psych-010418-102857 
Cohen, S., \& Williamson, G. M. (1988). Perceived stress in a probability sample of the United States. In S. Spacapan \& S. Oskamp (Eds.), The Social Psychology of Health. Newbury Park, CA: Sage.

Conroy, D., \& Hagger, M. S. (2018). Imagery interventions in health behavior: A metaanalysis. Health Psychology, 37(7), 668-679. doi: 10.1037/hea0000625

Crum, A. J., Akinola, M., Martin, A., \& Fath, S. (2017). The role of stress mindset in shaping cognitive, emotional, and physiological responses to challenging and threatening stress. Anxiety, Stress, \& Coping, 1-17. doi: 10.1080/10615806.2016.1275585

Crum, A. J., Salovey, P., \& Achor, S. (2013). Rethinking stress: The role of mindsets in determining the stress response. Journal of Personality and Social Psychology, 104(4), 716-733. doi: 10.1037/a0031201

Dweck, C. S., Chiu, C., \& Hong, Y. (1995). Implicit theories and their role in judgments and reactions: A word from two perspectives. Psychological Inquiry, 6(4), 267-285. doi: 10.1207/s15327965pli0604_1

Evans, J. S. (2008). Dual-processing accounts of reasoning, judgment, and social cognition. Annual Review of Psychology, 59, 255-278.

Evans, J. S., \& Stanovich, K. E. (2013). Dual-process theories of higher cognition: advancing the debate. Perspectives on Psychological Science, 8(3), 223-241. doi: $10.1177 / 1745691612460685$

Gollwitzer, P. M. (1999). Implementation intentions: Strong effects of simple plans. American Psychologist, 54(7), 493.

Hamilton, K., Keech, J. J., Peden, A. E., \& Hagger, M. S. (2019). Protocol for developing a mental imagery intervention: A randomised controlled trial testing a novel implementation imagery e-health intervention to change driver behaviour during floods. BMJ Open, O, e025565. doi: 10.1136/bmjopen-2018-025565 
Holmes, E. A., \& Mathews, A. (2005). Mental imagery and emotion. Emotion, 5(4), 489-497. doi: $10.1037 / 1528-3542.5 .4 .489$

Job, V., Dweck, C. S., \& Walton, G. M. (2010). Ego depletion-Is it all in your head? Implicit theories about willpower affect self-regulation. Psychological Science, 21(11), 1686-1693. doi: 10.1177/0956797610384745

Kavanagh, D. J., Andrade, J., \& May, J. (2005). Imaginary relish and exquisite torture: the elaborated intrusion theory of desire. Psychological Review, 112(2), 446-467.

Keech, J. J., Hagger, M. S., O’Callaghan, F. V., \& Hamilton, K. (2018). The influence of university students' stress mindsets on health and performance outcomes. Annals of Behavioral Medicine, 52(12), 1046-1059. doi: 10.1093/abm/kay008

Keech, J. J., \& Hamilton, K. (2019). Stress mindset. In M. D. Gelman (Ed.), Encyclopedia of behavioral medicine (2nd ed.). New York, NY: Springer Nature.

Kosslyn, S. M., \& Moulton, S. T. (2009). Mental imagery and implicit memory. In K. D. Markman, W. M. P. Klein \& J. A. Suhr (Eds.), Handbook of imagination and mental simulation. New York, NY: Taylor \& Francis.

Larcombe, W., Finch, S., Sore, R., Murray, C. M., Kentish, S., Mulder, R. A., . . . Williams, D. A. (2016). Prevalence and socio-demographic correlates of psychological distress among students at an Australian university. Studies in Higher Education, 41(6), 10741091. doi: 10.1080/03075079.2014.966072

Lazarus, R. S., \& Launier, R. (1978). Stress-related transactions between person and environment. In L. A. Pervin \& M. Lewis (Eds.), Perspectives in Interactional Psychology (pp. 287-327): Springer.

Liu, J. J., Vickers, K., Reed, M., \& Hadad, M. (2017). Re-conceptualizing stress: Shifting views on the consequences of stress and its effects on stress reactivity. PLoS ONE, 12(3). doi: 10.1371/journal.pone.0173188 
Lovallo, W. R. (2015). Stress and health: Biological and psychological interactions (3rd ed.). Thousand Oaks, CA: Sage.

Maniaci, M. R., \& Rogge, R. D. (2014). Caring about carelessness: Participant inattention and its effects on research. Journal of Research in Personality, 48, 61-83. doi: 10.1016/j.jrp.2013.09.008

Multhaupt, G., \& Beuth, J. (2018). The use of imagery in athletic injury rehabilitation. A systematic review. Deutsche Zeitschrift für Sportmedizin, 69(3), 57-64. doi: $10.5960 /$ dzsm.2018.316

Oettingen, G., Mayer, D., Timur Sevincer, A., Stephens, E. J., Pak, H.-j., \& Hagenah, M. (2009). Mental contrasting and goal commitment: The mediating role of energization. Personality and Social Psychology Bulletin, 35(5), 608-622. doi: $10.1177 / 0146167208330856$

Park, D., Yu, A., Metz, S. E., Tsukayama, E., Crum, A. J., \& Duckworth, A. L. (2018). Beliefs About Stress Attenuate the Relation Among Adverse Life Events, Perceived Distress, and Self-Control. Child Development, 89(6), 2059-2069. doi: 10.1111/cdev.12946

Pham, L. B., \& Taylor, S. E. (1999). From thought to action: Effects of process-versus outcome-based mental simulations on performance. Personality and Social Psychology Bulletin, 25(2), 250-260.

R Core Team. (2019). R: A language and environment for statistical computing. R Foundation for Statistical Computing. Vienna, Austria: R Foundation for Statistical Computing. Retrieved from https://www.R-project.org/

Ree, M. J., French, D., MacLeod, C., \& Locke, V. (2008). Distinguishing cognitive and somatic dimensions of state and trait anxiety: Development and validation of the 
State-Trait Inventory for Cognitive and Somatic Anxiety (STICSA). Behavioural and Cognitive Psychotherapy, 36(3), 313-332. doi: 10.1017/S1352465808004232

Rosseel, Y. (2012). Lavaan: An R package for structural equation modeling. Journal of Statistical Software, 48(2), 1-36. doi: http://www.jstatsoft.org/v48/i02/

Schaufeli, W. B., Salanova, M., González-Romá, V., \& Bakker, A. B. (2002). The measurement of engagement and burnout: A two sample confirmatory factor analytic approach. Journal of Happiness Studies, 3(1), 71-92. doi: 10.1023/A:1015630930326

Schnauber-Stockmann, A., Meier, A., \& Reinecke, L. (2018). Procrastination out of habit? The role of impulsive versus reflective media selection in procrastinatory media use. Media Psychology, 21(4), 640-668. doi: 10.1080/15213269.2018.1476156

Schroder, H. S., Dawood, S., Yalch, M. M., Donnellan, M. B., \& Moser, J. S. (2016). Evaluating the domain specificity of mental health-related mind-sets. Social Psychological and Personality Science, 7(6), 508-520. doi:

\section{$10.1177 / 1948550616644657$}

Schulz, K. F., Altman, D. G., Moher, D., \& the CONSORT Group. (2010). CONSORT 2010 Statement: updated guidelines for reporting parallel group randomised trials. $B M C$ Medicine, 8, 18. doi: 10.1186/1741-7015-8-18

Stallman, H. M. (2010). Psychological distress in university students: A comparison with general population data. Australian Psychologist, 45(4), 249-257. doi: $10.1080 / 00050067.2010 .482109$

Stanley, D. M., \& Cumming, J. (2010). Not just how one feels, but what one images? The effects of imagery use on affective responses to moderate exercise. International Journal of Sport and Exercise Psychology, 8, 343-359. doi:

10.1080/1612197X.2010.9671957 
Strack, F., \& Deutsch, R. (2004). Reflective and impulsive determinants of social behavior. Personality and Social Psychology Review, 8(3), 220-247. doi: 10.1207/s15327957pspr0803_1

Tamir, M., Bigman, Y. E., \& Pietromonaco, P. R. (2018). Expectations influence how emotions shape behavior. Emotion, 18(1), 15-25. doi: 10.1037/emo0000351

Tamir, M., Bigman, Y. E., Rhodes, E., Salerno, J., \& Schreier, J. (2015). An expectancy-value model of emotion regulation: Implications for motivation, emotional experience, and decision making. Emotion, 15(1), 90-103. doi: 10.1037/emo0000021

Tennant, R., Hiller, L., Fishwick, R., Platt, S., Joseph, S., Weich, S., . . Stewart-Brown, S. (2007). The Warwick-Edinburgh mental well-being scale (WEMWBS): development and UK validation. Health and Quality of Life Outcomes, 5:63. doi: 10.1186/1477$7525-5-63$

Vasquez, N. A., \& Buehler, R. (2007). Seeing future success: Does imagery perspective influence achievement motivation? Personality and Social Psychology Bulletin, 33(10), 1392-1405. doi: 10.1177/0146167207304541

Walton, G. M. (2014). The new science of wise psychological interventions. Current Directions in Psychological Science, 23(1), 73-82. doi: 10.1177/0963721413512856

Walton, G. M., \& Wilson, T. D. (2018). Wise interventions: Psychological remedies for social and personal problems. Psychological Review, 125(5), 617-655. doi: $10.1037 /$ rev0000115

Watson, D., Clark, L. A., \& Tellegen, A. (1988). Development and validation of brief measures of positive and negative affect: the PANAS scales. Journal of Personality and Social Psychology, 54(6), 1063-1070. doi: 10.1037/0022-3514.54.6.1063

Weibull, F., Cumming, J., Cooley, S. J., Williams, S. E., \& Burns, V. E. (2015). Walk this way: A brief exercise imagery intervention increases 
barrier self-efficacy in women. Current Psychology, 34, 477-490. doi: 10.1007/s12144-0149271-0

Yeager, D. S., \& Dweck, C. S. (2012). Mindsets that promote resilience: When students believe that personal characteristics can be developed. Educational Psychologist, 47(4), 302-314. doi: 10.1080/00461520.2012.722805

Yeager, D. S., Lee, H. Y., \& Jamieson, J. P. (2016). How to improve adolescent stress responses: Insights from integrating implicit theories of personality and biopsychosocial models. Psychological Science, 27(8), 1078-1091. doi: $10.1177 / 0956797616649604$ 
Table 1

Estimated marginal means, standard errors, and confidence intervals of study variables by time and group $(n=139)$.

\begin{tabular}{|c|c|c|c|c|c|c|c|c|c|c|c|c|}
\hline & \multicolumn{6}{|c|}{ Baseline } & \multicolumn{6}{|c|}{ Follow-up } \\
\hline & \multicolumn{3}{|c|}{ Control } & \multicolumn{3}{|c|}{ Intervention } & \multicolumn{3}{|c|}{ Control } & \multicolumn{3}{|c|}{ Intervention } \\
\hline & $M$ & $S E$ & $99 \% \mathrm{CI}$ & $M$ & $S E$ & $99 \% \mathrm{CI}$ & $M$ & $S E$ & $99 \% \mathrm{CI}$ & $M$ & $S E$ & $99 \% \mathrm{CI}$ \\
\hline Stress mindset & 3.27 & .10 & $3.01,3.53$ & 3.35 & .10 & $3.09,3.61$ & 3.22 & .10 & $2.95,3.49$ & 4.02 & .10 & $3.75,4.29$ \\
\hline $\begin{array}{l}\text { Perceived } \\
\text { distress }\end{array}$ & 20.71 & .94 & $18.26,23.17$ & 18.96 & .95 & $16.49,21.43$ & 20.03 & .87 & $17.76,22.30$ & 17.52 & .88 & $15.24,19.81$ \\
\hline $\begin{array}{l}\text { Psychological } \\
\text { wellbeing }\end{array}$ & 43.39 & 1.22 & $40.19,46.58$ & 46.04 & 1.23 & $42.83,49.26$ & 44.33 & 1.22 & $41.15,47.51$ & 47.00 & 1.23 & $43.80,50.20$ \\
\hline Positive affect & 30.61 & .93 & $28.18,33.05$ & 31.73 & .94 & $29.27,34.18$ & 29.76 & .89 & $27.43,32.08$ & 32.07 & .90 & $29.73,34.42$ \\
\hline Negative affect & 25.23 & 1.00 & $22.63,27.83$ & 24.20 & 1.00 & $21.58,26.83$ & 23.24 & .94 & $20.78,25.71$ & 20.81 & .95 & $18.33,23.30$ \\
\hline Physical health & 3.17 & .12 & $2.86,3.49$ & 3.31 & .12 & $3.00,3.64$ & 3.16 & .13 & $2.83,3.48$ & 3.42 & .13 & $3.09,3.75$ \\
\hline $\begin{array}{l}\text { Proactive } \\
\text { behavior }\end{array}$ & 2.88 & .08 & $2.68,3.09$ & 3.07 & .08 & $2.80,3.20$ & 3.00 & .08 & $2.80,3.20$ & 3.32 & .08 & $3.12,3.52$ \\
\hline $\begin{array}{l}\text { Somatic } \\
\text { symptoms }\end{array}$ & 21.13 & .78 & $19.10,23.15$ & 20.64 & .78 & $18.60,22.68$ & 19.96 & .77 & $17.96,21.96$ & 19.07 & .77 & $17.06,21.09$ \\
\hline $\begin{array}{l}\text { Academic } \\
\text { performance }\end{array}$ & 4.93 & .13 & $4.60,5.26$ & 5.26 & .13 & $4.93,5.59$ & 4.93 & .16 & $4.50,5.35$ & 5.41 & .16 & $4.99,5.59$ \\
\hline $\begin{array}{l}\text { Academic } \\
\text { engagement }\end{array}$ & 4.25 & .11 & $3.96,4.54$ & 4.32 & .11 & $4.02,4.61$ & 4.27 & .11 & $3.98,4.56$ & 4.44 & .11 & $4.15,4.74$ \\
\hline
\end{tabular}

Note: Follow-up = Two-week follow-up post-intervention. Stress mindset was also measured immediately post-intervention $($ Control: $M=3.28, S E=$ $.10,99 \%$ CI [3.02, 3.55]; Intervention: $M=4.27, S E=.10,99 \%$ CI [4.01, 4.54]). Participants lost to attrition $(n=3)$ and participants excluded due to failing attention check questions $(n=8)$ are not included in estimates. Control group $n=70$; intervention group $n=69$. Due to missing data $n=109$ ( $n$ $=54$ control; $n=55$ intervention) participants were used for academic performance analyses. 
Table 2. Estimated marginal means, standard errors, and confidence intervals for subgroups

\begin{tabular}{|c|c|c|c|c|c|c|}
\hline & \multicolumn{3}{|c|}{ Baseline } & \multicolumn{3}{|c|}{ Follow-up } \\
\hline & $M$ & $S E$ & $95 \% \mathrm{CI}$ & $M$ & $S E$ & $95 \% \mathrm{CI}$ \\
\hline \multicolumn{7}{|l|}{ Stress mindset } \\
\hline Low PSS control & 3.68 & .14 & $3.40,3.95$ & 3.65 & .14 & $3.37,3.93$ \\
\hline Low PSS intervention & 3.39 & .12 & $3.15,3.64$ & 4.11 & .13 & $3.85,4.36$ \\
\hline High PSS control & 2.91 & .13 & $2.66,3.17$ & 2.85 & .14 & $2.58,3.11$ \\
\hline High PSS intervention & 3.29 & .15 & $3.00,3.58$ & 3.90 & .15 & $3.60,4.20$ \\
\hline \multicolumn{7}{|l|}{ Perceived stress } \\
\hline Low PSS control & 13.06 & .73 & $11.62,14.50$ & 14.67 & 1.04 & $12.62,16.72$ \\
\hline Low PSS intervention & 13.90 & .66 & $12.59,15.21$ & 14.90 & .94 & $13.04,16.76$ \\
\hline High PSS control & 27.54 & .69 & $26.18,28.90$ & 24.81 & .98 & $22.87,26.75$ \\
\hline High PSS intervention & 25.93 & .78 & $22.87,26.75$ & 21.14 & 1.11 & $18.95,23.33$ \\
\hline \multicolumn{7}{|l|}{ Psychological wellbeing } \\
\hline Low PSS control & 51.15 & 1.37 & $48.45,53.85$ & 49.67 & 1.61 & $46.47,52.86$ \\
\hline Low PSS intervention & 50.90 & 1.24 & $48.45,53.36$ & 49.90 & 1.47 & $47.00,52.80$ \\
\hline High PSS control & 39.57 & 1.29 & $33.91,39.01$ & 39.57 & 1.53 & $36.55,42.59$ \\
\hline High PSS intervention & 39.35 & 1.46 & $36.46,42.23$ & 43.00 & 1.72 & $39.59,46.41$ \\
\hline \multicolumn{7}{|l|}{ Positive affect } \\
\hline Low PSS control & 34.85 & 1.22 & $32.44,37.26$ & 32.76 & 1.25 & $30.28,35.23$ \\
\hline Low PSS intervention & 34.25 & 1.11 & $32.06,36.44$ & 32.98 & 1.14 & $30.73,35.22$ \\
\hline High PSS control & 26.84 & 1.15 & $24.56,29.11$ & 27.08 & 1.18 & $24.75,29.42$ \\
\hline High PSS intervention & 28.24 & 1.30 & $26.67,30.81$ & 30.83 & 1.33 & $28.19,33.47$ \\
\hline \multicolumn{7}{|l|}{ Negative affect } \\
\hline Low PSS control & 19.67 & 1.15 & $17.40,21.93$ & 18.00 & 1.18 & $15.67,20.34$ \\
\hline Low PSS intervention & 19.90 & 1.04 & $17.84,21.96$ & 18.25 & 1.07 & $16.13,20.37$ \\
\hline High PSS control & 30.19 & 1.08 & $28.05,32.33$ & 27.92 & 1.12 & $25.71,30.12$ \\
\hline High PSS intervention & 30.14 & 1.22 & $27.72,32.55$ & 24.35 & 1.26 & $21.85,26.84$ \\
\hline \multicolumn{7}{|l|}{ Physical health } \\
\hline Low PSS control & 3.85 & .15 & $3.56,4.14$ & 3.70 & .17 & $3.37,4.03$ \\
\hline Low PSS intervention & 3.70 & .13 & $3.44,3.96$ & 3.68 & .15 & $3.37,3.98$ \\
\hline High PSS control & 2.57 & .14 & $2.29,2.84$ & 2.68 & .16 & $2.36,2.99$ \\
\hline High PSS intervention & 2.79 & .16 & $2.48,3.10$ & 3.07 & .18 & $2.72,3.42$ \\
\hline \multicolumn{7}{|l|}{ Proactive behavior } \\
\hline Low PSS control & 3.21 & 1.02 & $3.01,3.41$ & 3.29 & .11 & $3.08,3.50$ \\
\hline Low PSS intervention & 3.30 & .09 & $3.12,3.48$ & 3.38 & .10 & $3.19,3.57$ \\
\hline High PSS control & 2.59 & .10 & $2.40,2.78$ & 2.73 & .10 & $2.54,2.93$ \\
\hline High PSS intervention & 2.75 & .11 & $2.53,2.96$ & 3.25 & .11 & $3.02,3.47$ \\
\hline \multicolumn{7}{|l|}{ Somatic symptoms } \\
\hline Low PSS control & 17.46 & .96 & $15.56,19.35$ & 16.73 & .98 & $14.78,18.67$ \\
\hline Low PSS intervention & 17.70 & .87 & $15.98,19.42$ & 16.43 & .89 & $14.66,18.19$ \\
\hline High PSS control & 24.41 & .91 & $22.62,26.20$ & 22.84 & .93 & $21.00,24.68$ \\
\hline High PSS intervention & 24.69 & 1.02 & $22.67,26.71$ & 22.72 & 1.05 & $20.65,24.80$ \\
\hline \multicolumn{7}{|l|}{ Academic performance } \\
\hline Low PSS control & 5.11 & .18 & $4.74,5.47$ & 5.34 & .24 & $4.88,5.81$ \\
\hline Low PSS intervention & 5.45 & .17 & $5.12,5.78$ & 5.48 & .21 & $5.06,5.91$ \\
\hline High PSS control & 4.78 & .17 & $4.44,5.11$ & 4.57 & .22 & $4.14,5.00$ \\
\hline High PSS intervention & 5.04 & .18 & $4.67,5.40$ & 5.32 & .24 & $4.86,5.79$ \\
\hline \multicolumn{7}{|l|}{ Academic engagement } \\
\hline Low PSS control & 4.56 & .16 & $4.24,4.87$ & 4.53 & .16 & $4.21,4.85$ \\
\hline Low PSS intervention & 4.46 & .14 & $4.18,4.75$ & 4.51 & .15 & $4.23,4.80$ \\
\hline High PSS control & 3.97 & .15 & $3.68,4.27$ & 4.04 & .15 & $3.74,4.34$ \\
\hline High PSS intervention & 4.11 & .17 & $3.78,4.45$ & 4.35 & .17 & $4.01,4.69$ \\
\hline
\end{tabular}

Stress mindset was also measured immediately post-intervention (Low PSS control: $M=3.79, S E=.13$, 95\%CI [3.52, 4.05]; Low PSS intervention: $M=4.38, S E=.12,95 \%$ CI [4.14, 4.62]; High PSS control: $M=$ 2.83, $S E=.13,95 \% \mathrm{CI}[2.59,3.08]$; High PSS intervention: $M=4.12, S E=.14,95 \%$ CI $[3.84,4.40]$ ). 


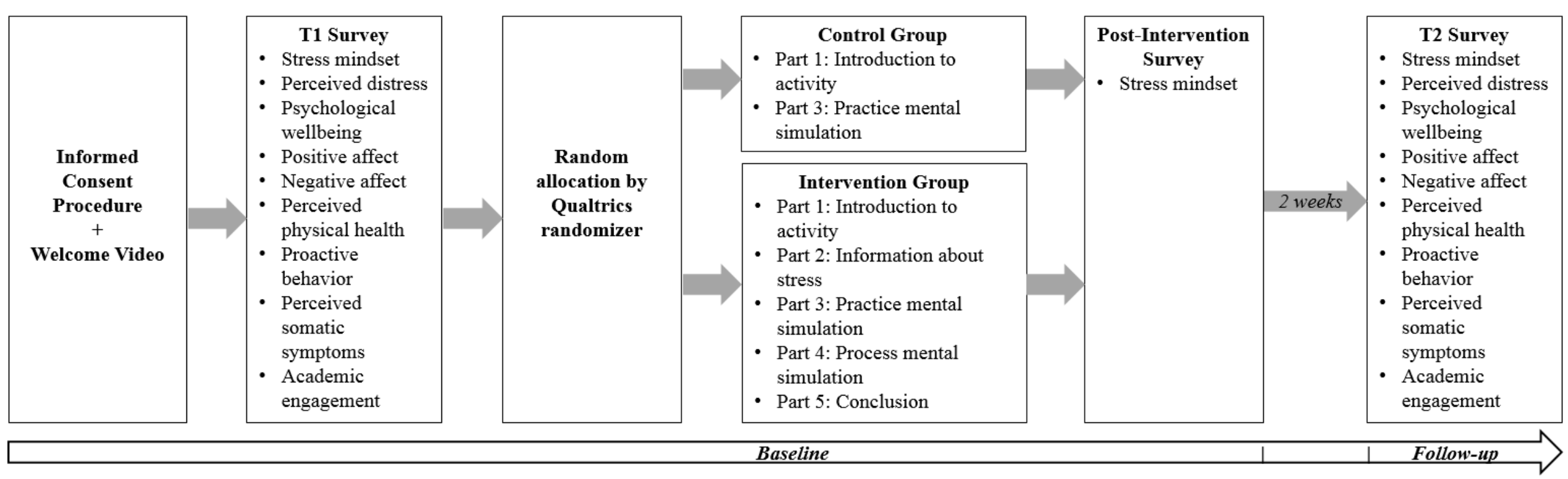

Figure 1. Randomized controlled trial design 


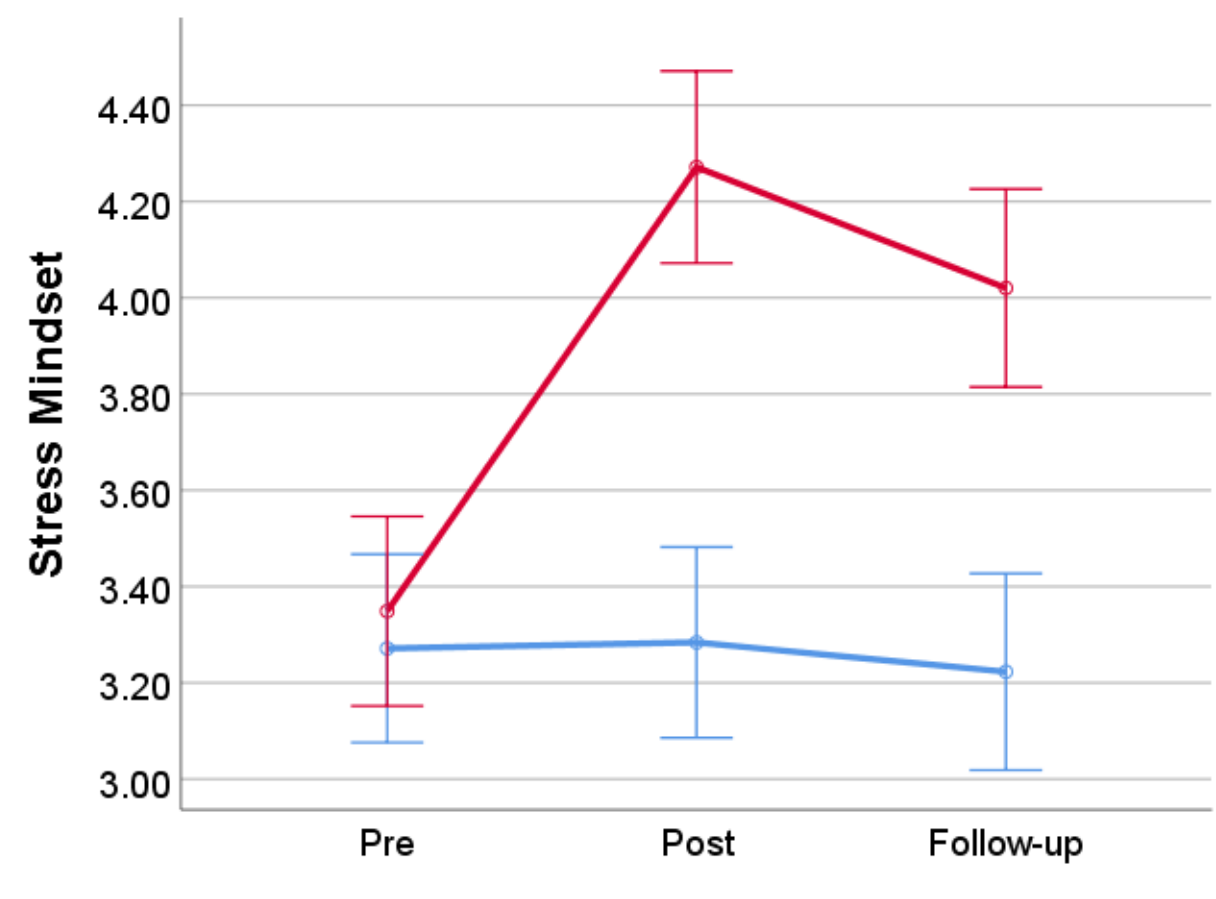

\section{Group \\ - Intervention \\ - Control}

\section{Time}

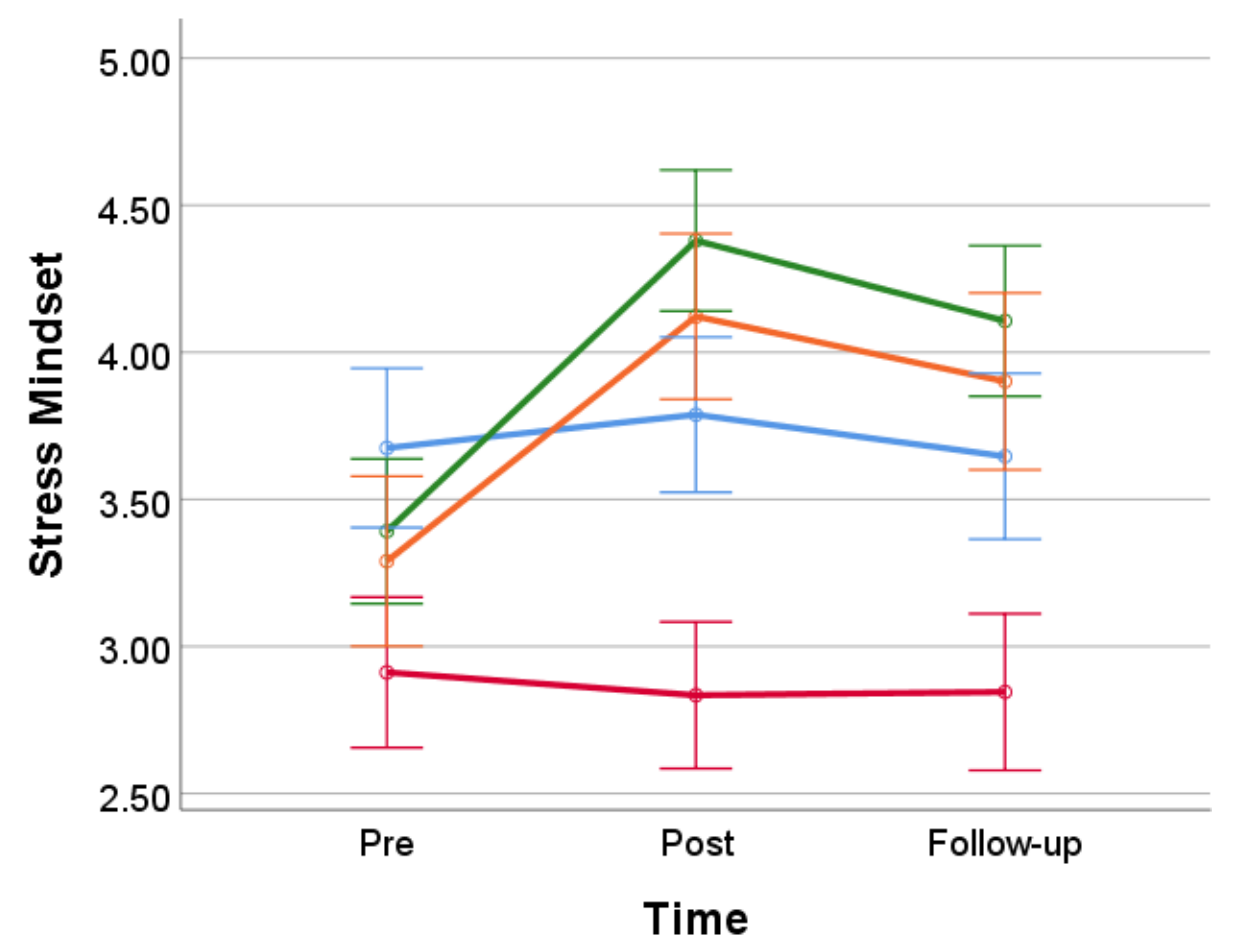

\section{Subgroup}

- Low PSS Control

- Low PSS Intervention

- High PSS Control

- High PSS Intervention

Figure 2. Stress mindset over time across intervention and control groups (top), and by subgroup (bottom). Intervention or control stimuli delivered between pre and post measures. Follow-up measure taken after two weeks. Error bars depict $95 \%$ confidence intervals. 

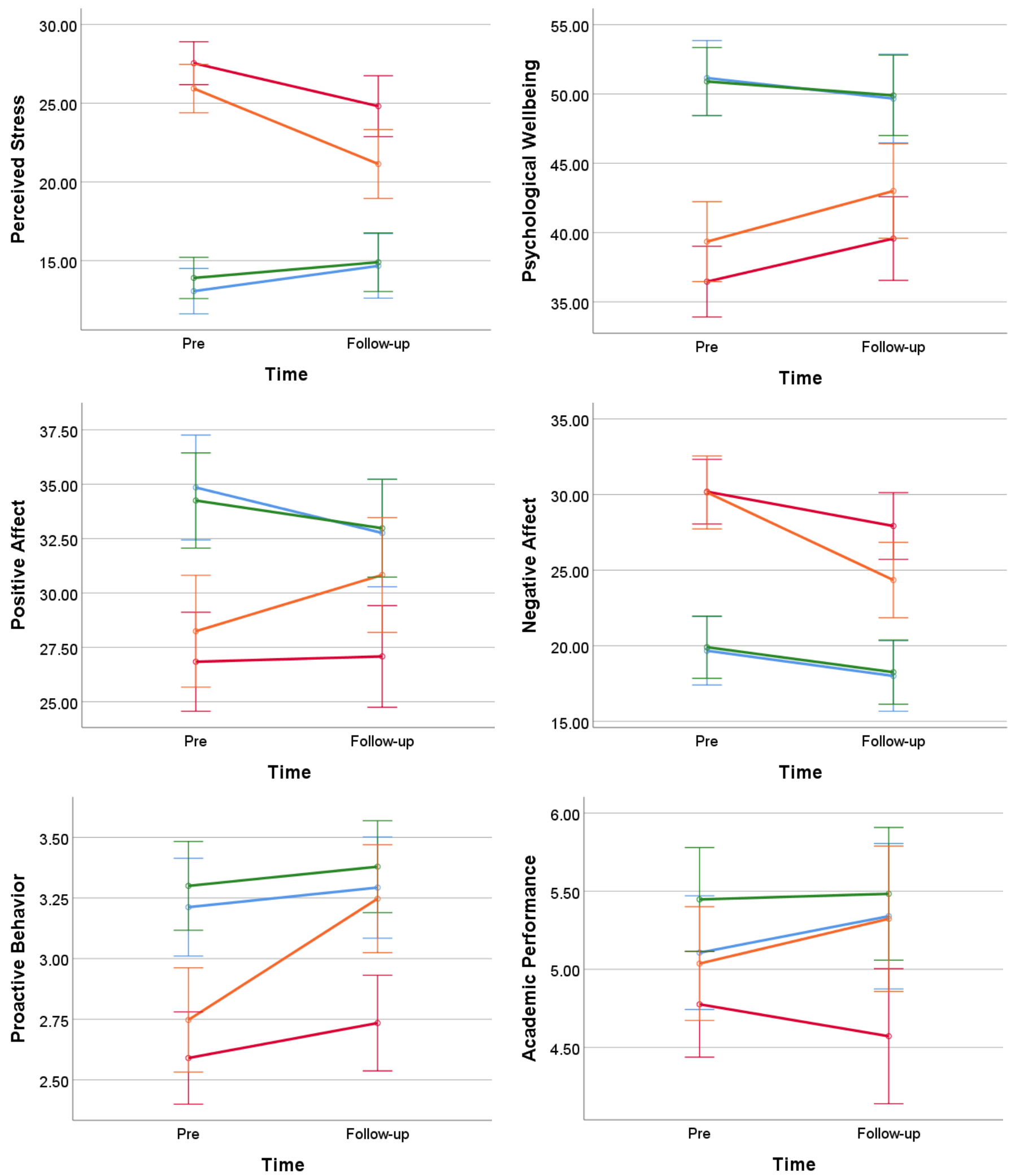

Subgroup

- Low PSS Control

- Low PSS Intervention

- High PSS Control

- High PSS Intervention

Figure 3. Secondary outcomes over time for intervention and control groups divided by baseline perceived distress where effects were observed for high baseline distress subgroup. Intervention or control condition stimuli delivered after pre measures. Follow-up measures taken two weeks later. Error bars depict 95\% confidence intervals. 

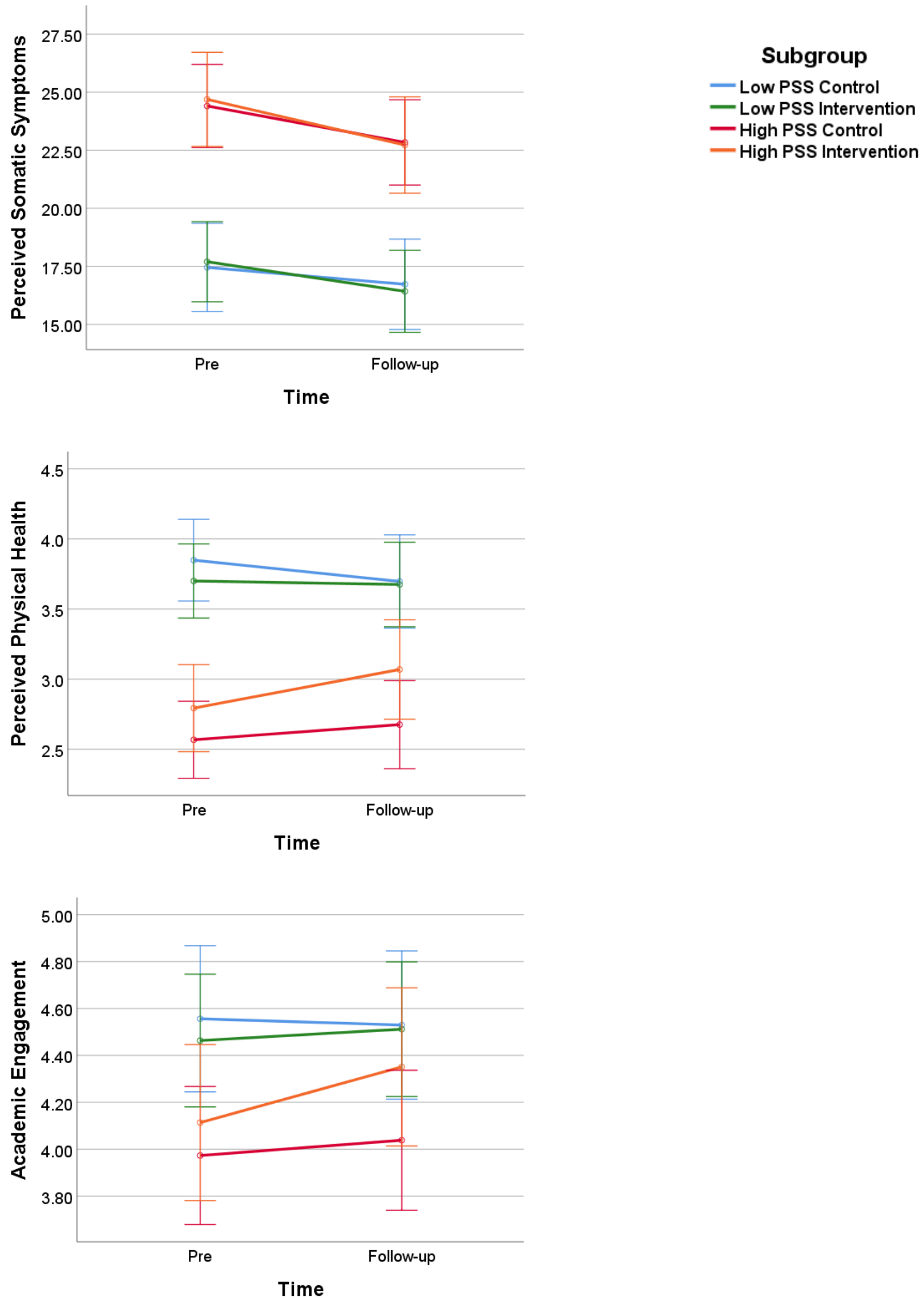

Figure 4. Secondary outcomes over time for intervention and control groups divided by baseline perceived distress where no significant effects were observed in either subgroup. Intervention or control condition stimuli delivered after pre measures. Follow-up measures taken two weeks later. 
Appendix A. Participant baseline demographic characteristics $(n=142)$

\begin{tabular}{|c|c|c|c|c|}
\hline Variable & $\begin{array}{l}\text { Total Sample } \\
\quad(n=142)\end{array}$ & $\begin{array}{c}\text { Intervention } \\
\quad(n=70)\end{array}$ & $\begin{array}{l}\text { Control } \\
(n=72)\end{array}$ & $p$-value ${ }^{\mathrm{a}}$ \\
\hline \multicolumn{5}{|l|}{ Gender } \\
\hline Male & $53(37.3 \%)$ & $25(34.7 \%)$ & $28(40.0 \%)$ & .52 \\
\hline Female & $89(62.7 \%)$ & $47(65.3 \%)$ & $42(60.0 \%)$ & \\
\hline Age & $19.08(1.92)$ & $19.10(1.76)$ & $19.07(2.08)$ & .94 \\
\hline \multicolumn{5}{|l|}{ Marital status } \\
\hline Never married & $141(99.3 \%)$ & $70(100 \%)$ & $71(98.6 \%)$ & .32 \\
\hline Married registered & $1(0.7 \%)$ & $0(0 \%)$ & $1(1.4 \%)$ & \\
\hline Children & & & & - \\
\hline Yes & $0(0 \%)$ & $0(0 \%)$ & $0(0 \%)$ & \\
\hline No & $142(100 \%)$ & $70(100 \%)$ & $72(100 \%)$ & \\
\hline \multicolumn{5}{|l|}{ Study load } \\
\hline Full-time & $135(95.1 \%)$ & $67(93.1 \%)$ & $68(97.1 \%)$ & .26 \\
\hline Part-time & $7(4.9 \%)$ & $5(6.9 \%)$ & $2(2.9 \%)$ & \\
\hline \multicolumn{5}{|l|}{ Employment status } \\
\hline Studying only & $51(35.9 \%)$ & $30(41.7 \%)$ & $21(30.0 \%)$ & .23 \\
\hline Full-time work & $1(0.7 \%)$ & $0(0 \%)$ & $1(1.4 \%)$ & \\
\hline Part-time work & $90(63.4 \%)$ & $42(58.3 \%)$ & $48(68.6 \%)$ & \\
\hline Work hours & $9.65(9.45)$ & $8.78(9.43)$ & $10.53(9.46)$ & .27 \\
\hline \multicolumn{5}{|c|}{ Personal income (Weekly) } \\
\hline Nil income & $39(27.5 \%)$ & $23(31.9 \%)$ & $16(22.9 \%)$ & .48 \\
\hline$\$ 1-\$ 199$ & $34(23.9 \%)$ & $14(19.4 \%)$ & $20(28.6 \%)$ & \\
\hline$\$ 200-\$ 299$ & $30(21.1 \%)$ & $14(19.4 \%)$ & $16(22.9 \%)$ & \\
\hline$\$ 300-\$ 399$ & $14(9.9 \%)$ & $10(13.9 \%)$ & $4(5.7 \%)$ & \\
\hline$\$ 400-\$ 599$ & $17(12.0 \%)$ & $7(9.7 \%)$ & $10(14.3 \%)$ & \\
\hline$\$ 600-\$ 799$ & $4(2.8 \%)$ & $2(2.8 \%)$ & $2(2.9 \%)$ & \\
\hline$\$ 800-\$ 999$ & $2(1.4 \%)$ & $1(1.4 \%)$ & $1(1.4 \%)$ & \\
\hline$\$ 1,000-\$ 1,249$ & $1(0.7 \%)$ & $0(0 \%)$ & $1(1.4 \%)$ & \\
\hline$\$ 1,250-\$ 1,499$ & $0(0 \%)$ & $0(0 \%)$ & $0(0 \%)$ & \\
\hline$\$ 1,500-\$ 1,999$ & $1(0.7 \%)$ & $1(1.4 \%)$ & $0(0 \%)$ & \\
\hline$\$ 2,000$ and above & $0(0 \%)$ & $0(0 \%)$ & $0(0 \%)$ & \\
\hline \multicolumn{5}{|l|}{ ESOL } \\
\hline Yes & $40(28.2 \%)$ & $22(30.6 \%)$ & $18(25.7 \%)$ & .52 \\
\hline No & $102(71.8 \%)$ & $50(69.4 \%)$ & $52(74.3 \%)$ & \\
\hline \multicolumn{5}{|l|}{ Student type } \\
\hline Domestic & $136(95.8 \%)$ & $136(93.1 \%)$ & $69(98.6 \%)$ & .10 \\
\hline International & $6(4.2 \%)$ & $6(6.9 \%)$ & $1(1.4 \%)$ & \\
\hline Imagery ability & $3.66(.45)$ & $3.67(.43)$ & $3.66(.47)$ & .87 \\
\hline
\end{tabular}

${ }^{a}$ Independent samples $t$-test used for comparing continuous data, chi-square test used for comparing categorical data, between intervention and control groups. 
Appendix B. Consort flow diagram of participant progression through the study

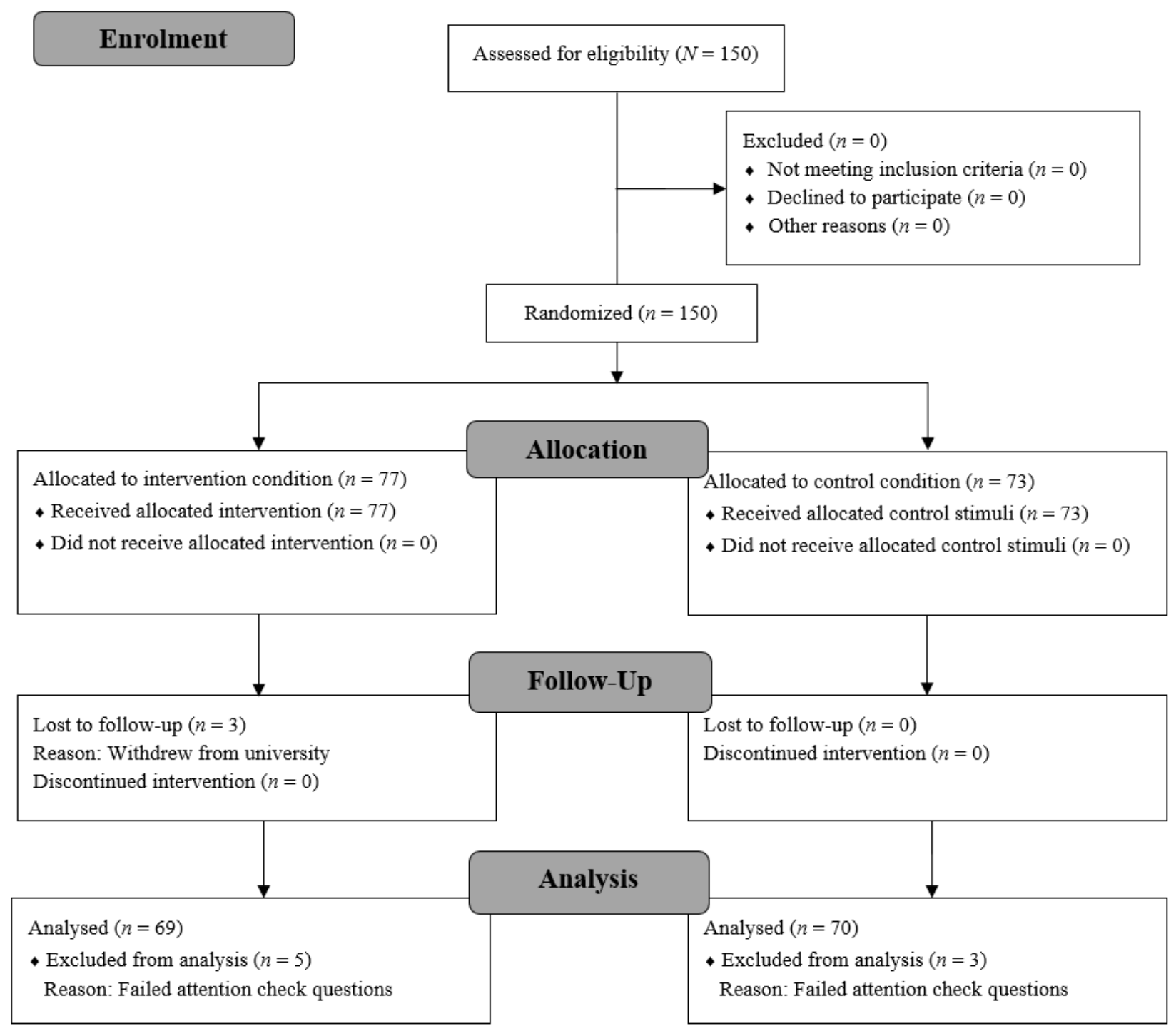

Note: Potential participants were advised of eligibility criteria prior to indicating interest in participating. Participants self-enrolled and all that were screened were eligible. 
CHANGING STRESS MINDSET WITH MENTAL IMAGERY

Appendix C. Items and Response Scales for Study Variables

\begin{tabular}{|c|c|c|c|c|}
\hline Construct & Measure & $\alpha$ & Items & Scale/Scoring \\
\hline Stress mindset & $\begin{array}{l}\text { SCMM (Keech } \\
\text { et al., 2018) }\end{array}$ & $\begin{array}{l}\text { Baseline: .93 } \\
\text { Post- } \\
\text { intervention: } \\
.95 \\
\text { Follow-up: } .95\end{array}$ & $\begin{array}{l}\text { You are unable to use stress to enhance your performance and productivity* } \\
\text { Stress can be used as a way to get the most out of your life } \\
\text { Stress can be used to enhance your health and vitality } \\
\text { Stress must be reduced or avoided to get the most out of life* } \\
\text { You can use stress to boost your performance and productivity } \\
\text { Stress will impair your health and vitality* } \\
\text { Stress can be used to enhance your performance and productivity } \\
\text { You can use stress to stimulate your health and vitality } \\
\text { Stress can be used to enhance your learning and growth } \\
\text { The effect of stress on you is negative* } \\
\text { You are unable to use stress to enhance your learning and growth* } \\
\text { You are unable to use stress to enhance your health and vitality* } \\
\text { Stress will impair your learning and growth* } \\
\text { Stress will impair your performance and productivity* } \\
\text { You can use stress to facilitate your learning and growth }\end{array}$ & $\begin{array}{l}1=\text { strongly } \\
\text { disagree, } \\
6=\text { strongly } \\
\text { agree / Scale } \\
\text { calculated: mean }\end{array}$ \\
\hline $\begin{array}{l}\text { Perceived } \\
\text { distress }\end{array}$ & $\begin{array}{l}\text { PSS-10 (Cohen } \\
\text { \& Williamson, } \\
\text { 1988) }\end{array}$ & $\begin{array}{l}\text { Baseline: .91 } \\
\text { Follow-up: .90 }\end{array}$ & See Cohen and Williamson (1988) for items. & $\begin{array}{l}0=\text { never } \\
4=\text { very often } / \\
\text { Scale calculated } \\
\text { sum }\end{array}$ \\
\hline Affect & $\begin{array}{l}\text { PANAS-SF } \\
\text { (Watson et al., } \\
1988 \text { ) }\end{array}$ & $\begin{array}{l}\text { Positive- } \\
\text { Baseline: } .90 \\
\text { Follow-up: } .91 \\
\text { Negative- } \\
\text { Baseline: } .88 \\
\text { Follow-up: } .90\end{array}$ & See Watson et al. (1988) for items. & $\begin{array}{l}1=\text { very slightly } \\
\text { or not at all, } 5= \\
\text { extremely / } \\
\text { Scale calculated: } \\
\text { sum }\end{array}$ \\
\hline $\begin{array}{l}\text { Proactive } \\
\text { behavior }\end{array}$ & $\begin{array}{l}\text { Proactive under } \\
\text { stress scale } \\
\text { (Keech et al., } \\
\text { 2018) }\end{array}$ & $\begin{array}{l}\text { Baseline: .74 } \\
\text { Follow-up: .78 }\end{array}$ & $\begin{array}{l}\text { In the last month, how often were you proactive to cope with stress? } \\
\text { In the last month, how often were you not proactive when under stress?* } \\
\text { In the last month, how often did you engage in planning your time to cope with stress? } \\
\text { In the last month, how often did you avoid engaging in planning your time when under } \\
\text { stress?* } \\
\text { In the last month, how often did you avoid procrastination to cope with stress? }\end{array}$ & $\begin{array}{l}1=\text { never } \\
5=\text { very often } / \\
\text { Scale calculated } \\
\text { mean }\end{array}$ \\
\hline
\end{tabular}




\begin{tabular}{|c|c|c|c|c|}
\hline & & & In the last month, how often did you procrastinate when under stress?* & \\
\hline $\begin{array}{l}\text { Physical } \\
\text { wellbeing }\end{array}$ & $\begin{array}{l}\text { HRQOL-14 } \\
\text { Question } 1 \\
\text { (Centers for } \\
\text { Disease Control } \\
\text { and Prevention., } \\
\text { 2000) }\end{array}$ & - & Would you say that in general your health is: & $\begin{array}{l}1=\text { excellent } \\
5=\text { poor } / \\
\text { Reverse-coded } \\
\text { for analysis }\end{array}$ \\
\hline $\begin{array}{l}\text { Perceived } \\
\text { general } \\
\text { somatic } \\
\text { symptoms }\end{array}$ & $\begin{array}{l}\text { STICSA-T } \\
\text { somatic subscale } \\
\text { (Ree et al., } \\
\text { 2008; Ree, } \\
\text { MacLeod, } \\
\text { French, \& } \\
\text { Locke, 2000) }\end{array}$ & $\begin{array}{l}\text { Baseline: } .87 \\
\text { Follow-up: } .89\end{array}$ & See Ree et al. (2008) for items. & $\begin{array}{l}1=\text { almost } \\
\text { never, } \\
4=\text { almost } \\
\text { always / Scale } \\
\text { calculated: sum }\end{array}$ \\
\hline $\begin{array}{l}\text { Academic } \\
\text { performance }\end{array}$ & $\begin{array}{l}\text { Official } \\
\text { university } \\
\text { records }\end{array}$ & - & $\begin{array}{l}\text { The grade point average (GPA) score is measured on a } 1-7 \text { scale, with scores from 1-3 } \\
\text { indicating an average grade of less than } 50 \%, 4 \text { indicating an average grade between } 50- \\
64 \%, 5 \text { indicating an average grade between } 65-74 \%, 6 \text { indicating an average grade of } 75- \\
84 \% \text {, and } 7 \text { indicating an average grade of } 85 \% \text { or greater. }\end{array}$ & \\
\hline $\begin{array}{l}\text { Academic } \\
\text { engagement }\end{array}$ & $\begin{array}{l}\text { (UWES-S) } \\
\text { (Schaufeli et al., } \\
\text { 2002) }\end{array}$ & $\begin{array}{l}\text { Baseline: .92 } \\
\text { Follow-up: .93 }\end{array}$ & See Schaufeli et al. (2002) for items. & $\begin{array}{l}0=\text { never, } 6= \\
\text { always / Scale } \\
\text { calculated: mean }\end{array}$ \\
\hline Imagery ability & $\begin{array}{l}\text { International } \\
\text { Personality Item } \\
\text { Pool factor V } \\
\text { (intellect and } \\
\text { imagination) of } \\
\text { Goldberg's Big- } \\
\text { Five Factor } \\
\text { Markers } \\
\text { (Goldberg, } \\
\text { 1992, 1999) }\end{array}$ & .68 & $\begin{array}{l}\text { Typically, I... Have a rich vocabulary } \\
\text { Typically, I... Have difficulty understanding abstract ideas } \\
\text { Typically, I... Have a vivid imagination } \\
\text { Typically, I... Am not interested in abstract ideas } \\
\text { Typically, I... Have excellent ideas } \\
\text { Typically, I... Do not have a good imagination } \\
\text { Typically, I... Am quick to understand things } \\
\text { Typically, I... Use difficult words } \\
\text { Typically, I... Spend time reflecting on things } \\
\text { Typically, I... Am full of ideas }\end{array}$ & $\begin{array}{l}1=\text { very } \\
\text { inaccurate, } 5= \\
\text { very accurate / } \\
\text { Scale calculated: } \\
\text { mean }\end{array}$ \\
\hline
\end{tabular}




\section{CHANGING STRESS MINDSET WITH MENTAL IMAGERY}

Appendix D. Secondary outcomes over time across intervention and control groups for pre-registered analyses. Intervention or control condition stimuli delivered after pre measures. Follow-up measures taken two weeks later.
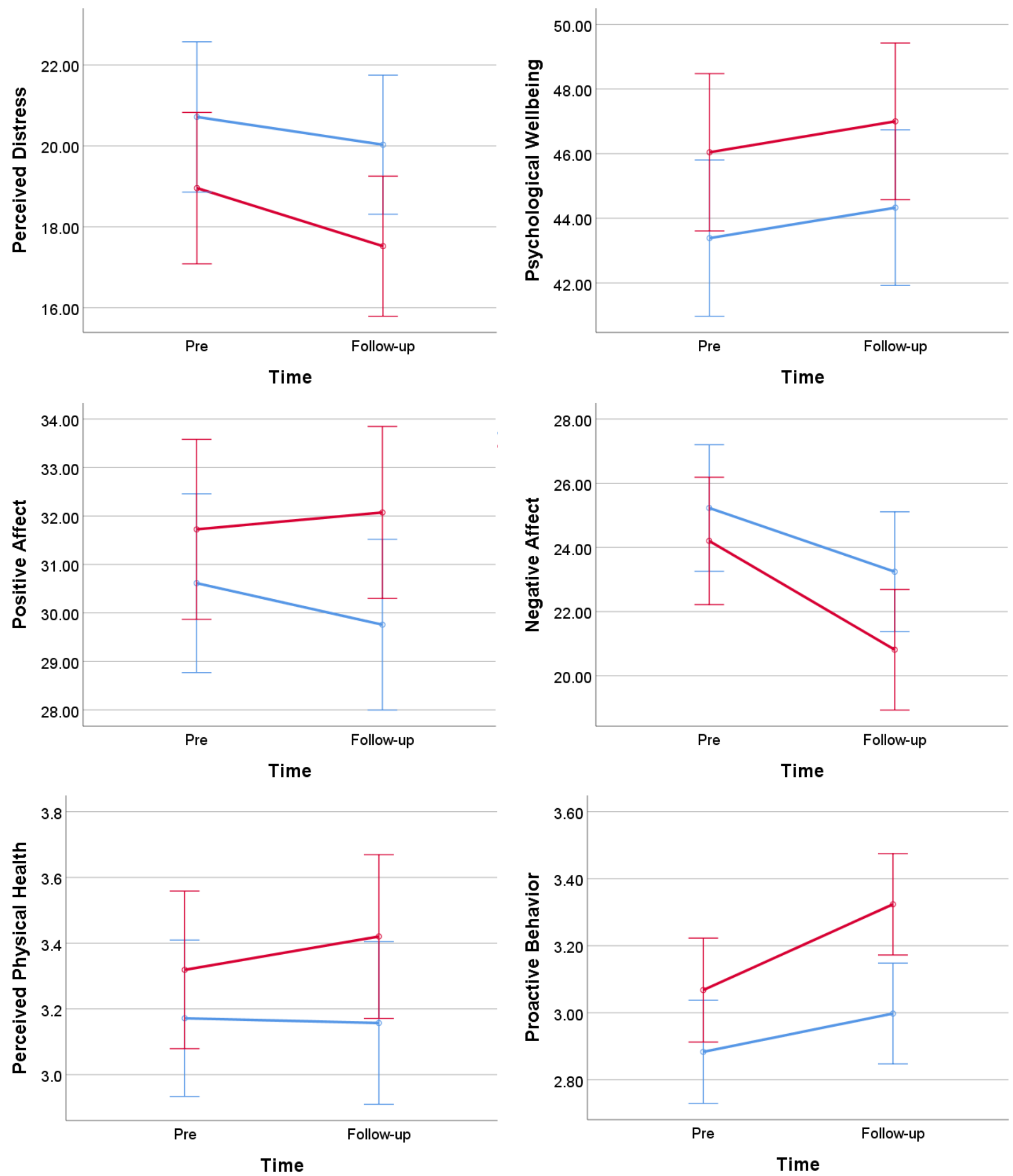
CHANGING STRESS MINDSET WITH MENTAL IMAGERY
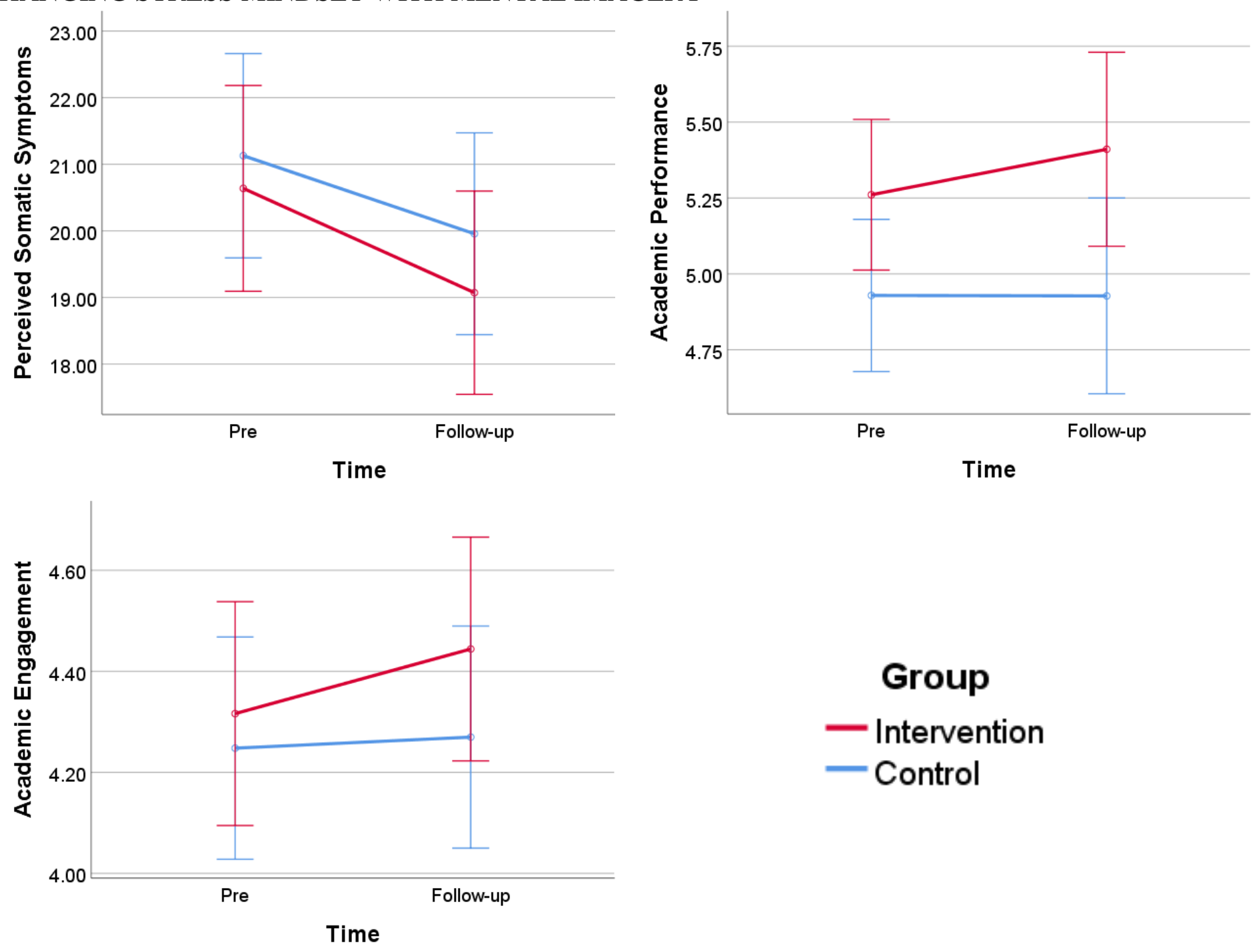


\section{Appendix E. Ancillary analyses}

\section{Ancillary Analyses 1}

A series of regression analyses were conducted using the maximum-likelihood estimator in $R$ (R Core Team, 2019) using the lavaan (Rosseel, 2012) package. Dependent variables were the follow-up value for each outcome. Baseline values of the dependent variable, group, and baseline values of psychological wellbeing, proactive behavior, academic performance were entered as predictors. Missing data was estimated using the full-information maximum likelihood (FIML) procedure.

Stress mindset. The overall model predicted significant variance in stress mindset immediately postintervention $\left(R^{2}=.64, p<.001\right)$. A significant main effect of group on post-intervention stress mindset scores was also observed $(B=.89,95 \%$ CI $[.70,1.09], S E=.10, \beta=.46, p<.001)$. Similarly, the overall model predicted significant variance in follow-up stress mindset scores $\left(R^{2}=.63, p<.001\right)$. A significant main effect of group on follow-up stress mindset scores was also observed ( $B=.69,95 \%$ CI $[.50, .89], S E=$ $.10, \beta=.37, p<.001)$.

Perceived stress. The overall model predicted significant variance in follow-up psychological wellbeing $\left(R^{2}\right.$ $=.48, p<.001)$. However, no significant main effect of group on follow-up psychological wellbeing was observed $(B=-1.56,95 \%$ CI $[-3.37, .26], S E=.93, \beta=-.11, p=.093)$.

Psychological wellbeing. The overall model predicted significant variance in follow-up psychological wellbeing $\left(R^{2}=.41, p<.001\right)$. However, no significant main effect of group on follow-up psychological wellbeing was observed $(B=.80,95 \%$ CI $[-1.89,3.50], \beta=.04, p=.558)$.

Positive affect. The overall model predicted significant variance in follow-up positive affect $\left(R^{2}=.41, p<\right.$ $.001)$. However, no significant main effect of group on follow-up positive affect was observed $(B=1.41$, $95 \%$ CI [-.56, 3.38], SE $=1.00, \beta=.09, p=.161)$.

Negative affect. The overall model predicted significant variance in follow-up negative affect $\left(R^{2}=.43, p<\right.$ $.001)$. However, no significant main effect of group on follow-up negative affect was observed $(B=-1.63$, $95 \%$ CI $[-3.67, .42], S E=1.04, \beta=-.10, p=.119)$.

Perceived physical health. The overall model predicted significant variance in follow-up perceived physical health $\left(R^{2}=.41, p<.001\right)$. However, no significant main effect of group on follow-up perceived physical health was observed $(B=.14,95 \% \mathrm{CI}[-.14, .42], S E=.14, \beta=.07, p=.316)$.

Proactive behavior. The overall model predicted significant variance in follow-up proactive behavior $\left(R^{2}=\right.$ $.45, p<.001)$. The main effect of group on follow-up proactive behavior was also approaching our specified cutoff for statistical significance $(B=.19,95 \% \mathrm{CI}[.02, .35], S E=.09, \beta=.15, p=.027)$.

Perceived somatic symptoms. The overall model predicted significant variance in follow-up perceived somatic symptoms $\left(R^{2}=.55, p<.001\right)$. However, no significant main effect of group on follow-up perceived somatic symptoms was observed $(B=-.34,95 \% \mathrm{CI}[-1.80,1.13], S E=.75, \beta=-.03, p=.649)$.

Academic performance. The overall model predicted significant variance in follow-up academic performance $\left(R^{2}=.71, p<.001\right)$. However, no significant main effect of group on follow-up academic performance was observed $(B=.07,95 \% \mathrm{CI}[-.18, .33], S E=.13, \beta=.03, p=.57)$.

Academic engagement. The overall model predicted significant variance in follow-up academic performance $\left(R^{2}=.67, p<.001\right)$. However, no significant main effect of group on follow-up academic engagement was observed $(B=.09,95 \%$ CI $[-.09, .28], S E=.09, \beta=.05, p=.33)$. 


\section{Ancillary Analyses 2}

Academic performance. The effect of the intervention on each subgroup was examined using a multi-group regression analysis in $R$ (R Core Team, 2019) using the lavaan (Rosseel, 2012) package to estimate missing data with the FIML procedure. For the low perceived stress subgroup, the overall model predicted significant variance in follow-up academic performance $\left(R^{2}=.70, p<.001\right)$. However, no significant main effect of group on follow-up academic performance was observed $(B=-.27,95 \%$ CI [-.61, .07], SE $=.17, \beta$ $=-.11, p=.119)$. For the high perceived stress subgroup, the overall model predicted significant variance in follow-up academic performance $\left(R^{2}=.72, p<.001\right)$. A main effect of group on follow-up academic performance was also observed $(B=.49,95 \%$ CI $[.13, .86], S E=.19, \beta=.19, p=.009)$. 